AperTO - Archivio Istituzionale Open Access dell'Università di Torino

Maths in the time of social media: conceptualizing the Internet phenomenon of mathematical memes

This is a pre print version of the following article:

Original Citation:

Availability:

This version is available http://hdl.handle.net/2318/1741501

since 2022-06-22T14:06:58Z

Published version:

DOI:10.1080/0020739X.2020.1807069

Terms of use:

Open Access

Anyone can freely access the full text of works made available as "Open Access". Works made available under a Creative Commons license can be used according to the terms and conditions of said license. Use of all other works requires consent of the right holder (author or publisher) if not exempted from copyright protection by the applicable law. 


\title{
Maths in the time of social media: conceptualizing the Internet phenomenon of mathematical memes
}

\author{
Giulia Bini $^{1 *}$, Ornella Robutti ${ }^{1}$, Angelika Bikner-Ahsbahs ${ }^{2}$ \\ ${ }^{1}$ Department of Mathematics, University of Turin, Italy, ${ }^{2}$ Faculty 3-Mathematics and \\ Computer Sciences, University of Bremen, Germany

\section{*giulia.bini@unito.it ornella.robutti@unito.it bikner@math.uni-bremen.de}

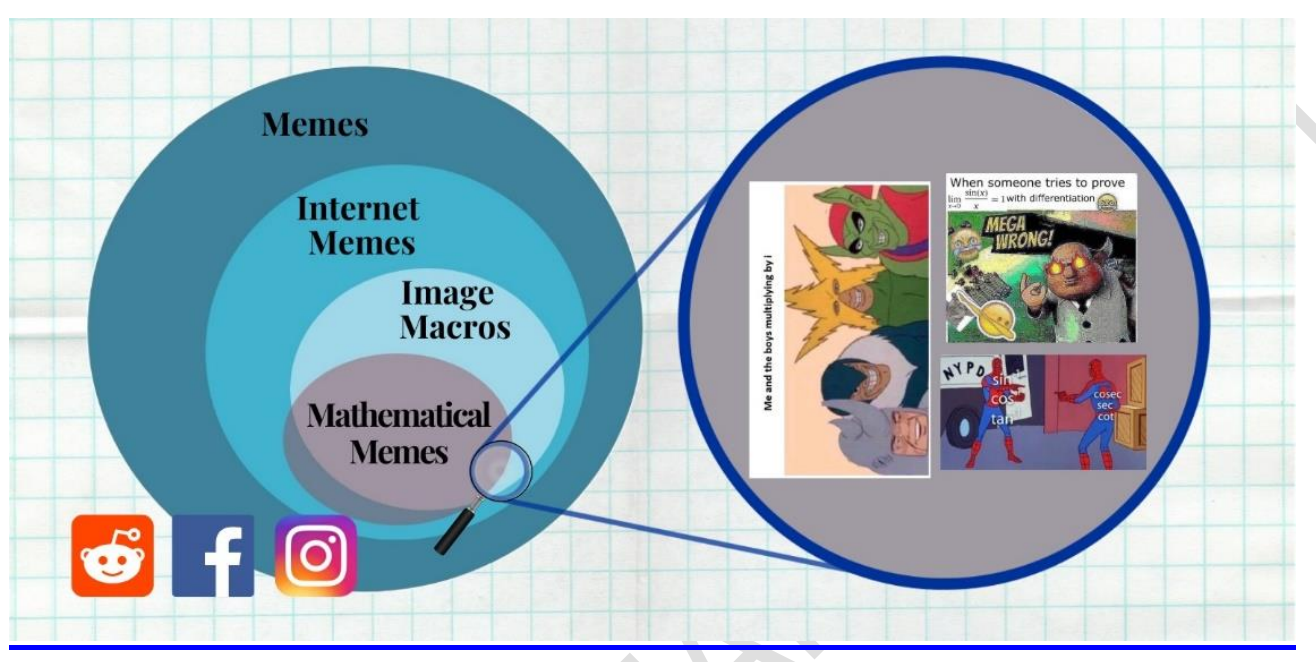

Mathematical memes are an Internet phenomenon with an epistemic potential noteworthy for the teaching and learning of mathematics. The aim of this paper is to conceptualize this phenomenon on an empirical base, elucidating its educational potential. To pursue this goal, a two-year ethnographic research has been conducted in a selection of social media communities that exchange mathematical memes. In the paper, a two-fold theoretical lens is used to investigate the phenomenon from a memetic perspective focused on the general characteristics of Internet memes, and from a cultural perspective considering the Web 2.0 environment. Analysis tools derived from the memetic and cultural theoretical background are applied to an instrumental case study, to reconstruct how mathematical memes activate the interaction among members of an online community. The investigation elicits key characteristics of the phenomenon, provides grounds to conceptualize mathematical memes as hybrid representations of mathematical statements, and sheds light on the traits of the epistemic culture they establish in the community.

Keywords: Internet meme, mathematics, social media, learning communities, epistemic need, mathematical statement, Web 2.0 culture

Though this be madness, yet there is method in it. Hamlet Act 2, scene 2, 203-204

This is the Accepted Manuscript of an article published by Taylor \& Francis in International Journal of Mathematical Education in Science and Technology on 26 September 2020, available at https://www.tandfonline.com/doi/full/10.1080/0020739X.2020.1807069 


\section{Introduction: purpose and object of the study}

Memes are humorous digital objects created by web users copying an existing image and overlaying a personal caption. Since their appearance in the late 90's, memes have been colonizing the web and their use spontaneously extended from the initial entertaining goals (Miltner, 2014) to encompass different subjects, including serious themes as politics (Huntington, 2017) and educational topics as mathematics (Benoit, 2018).

This research focuses on mathematical memes, an Internet phenomenon attracting communities of thousands of followers, still significantly under researched. The purpose of the study is to reach a conceptualization of the phenomenon that sheds light on its educational potentialities. To clarify the object of the study, we start with an example. The meme known as Me and the boys appeared in May 2019 on the popular social media website Reddit, when users started sharing posts with the same figurative element, a screenshot showing the villains from a 60's Spider-Man animated movie. This image, complemented by different captions all with the same Me and the boys incipit, was used to metaphorically represent a group of students doing things together, with a view to evoking nostalgic memories of schoolboys' lives (Figure 1a and $1 b)$.
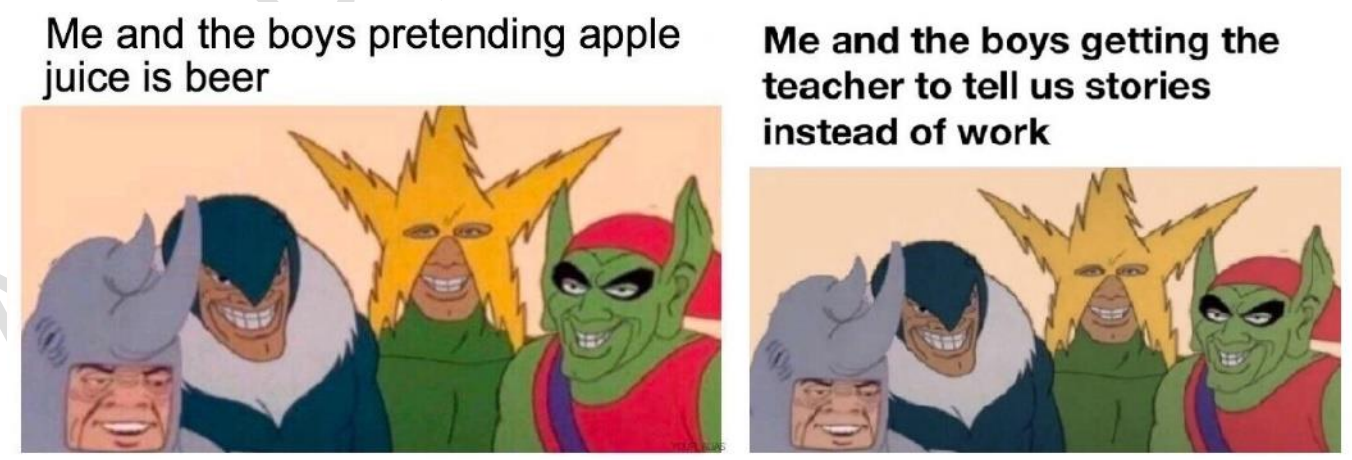

Figures 1(a) 1(b). Me and the boys mutations with different captions [source Reddit]

These posts were immediately widely liked and shared, and rapidly followed by others partaking the same evocative plot, differing in the textual part and in some alterations of the basic picture (Figure $2 \mathrm{a}$ and $2 \mathrm{~b}$ ).

This is the Accepted Manuscript of an article published by Taylor \& Francis in International Journal of Mathematical Education in Science and Technology on 26 September 2020, available at https://www.tandfonline.com/doi/full/10.1080/0020739X.2020.1807069 
Me and the boys in winter, exhaling air through our mouths to pretend we're smoking

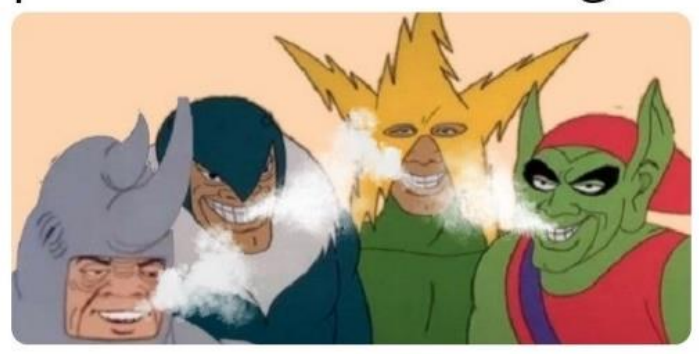

When one of the boys gets a girlfriend

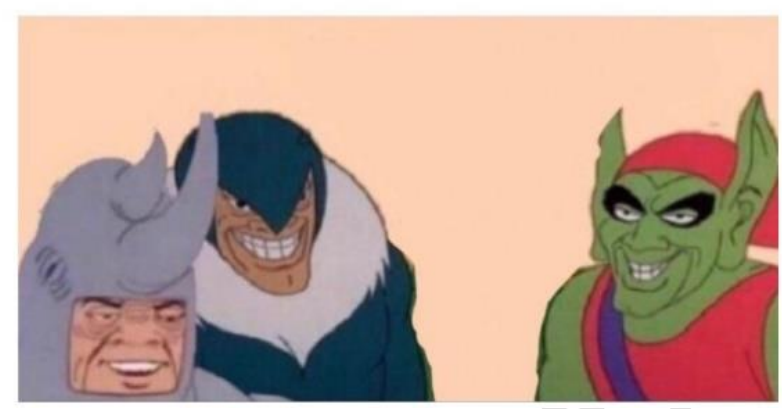

Figures 2(a) 2(b). Me and the boys mutations with edited images [source Reddit]

At the beginning of June 2019, two other users posted a couple of mathematical mutations of the Me and the boys post (Figure $3 \mathrm{a}$ and $3 \mathrm{~b}$ ), shifting the narrative from commonly shared schoolboys' memories to mathematical graduates' knowledge.
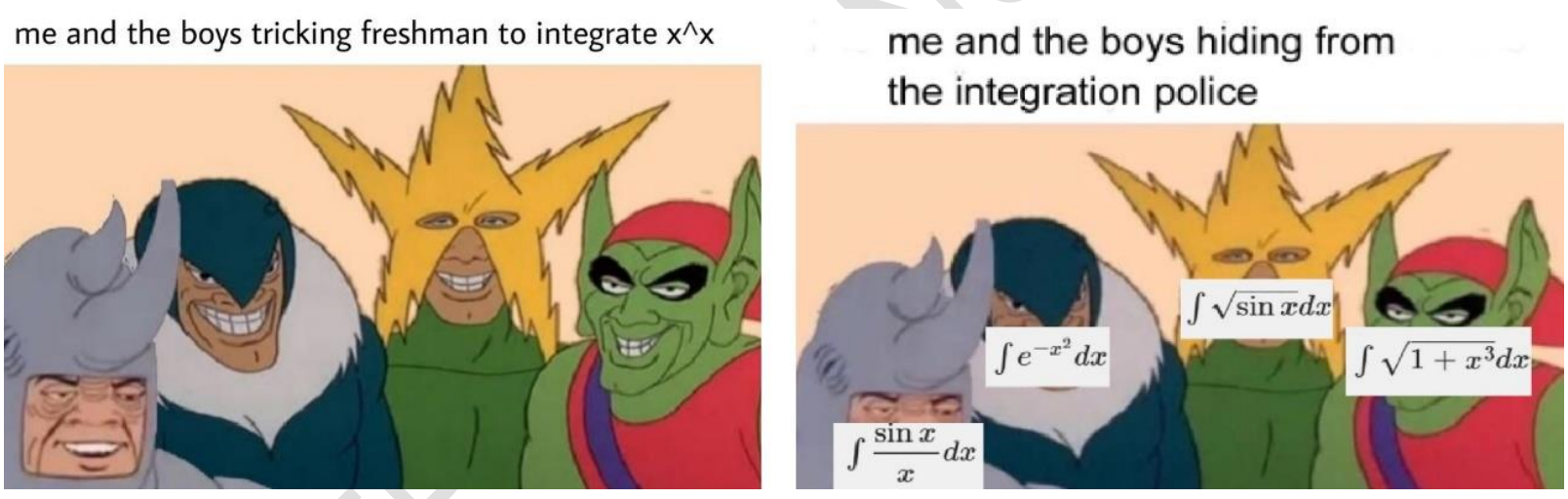

Figures 3(a) 3(b). Me and the boys first mathematical mutations [source Reddit and

Facebook]

At the end of June 2019, another mathematical mutation (Figure 4) appeared. This mutation, although implying the acquaintance with the iconographic part (the original Me and the boys' horizontal image), distances itself from the initial storyline, bending it (or we could say rotating it) to convey a hidden meaning, hinted by the text and accessible only to mathematically savvy viewers.

This is the Accepted Manuscript of an article published by Taylor \& Francis in International Journal of Mathematical Education in Science and Technology on 26 September 2020, available at https://www.tandfonline.com/doi/full/10.1080/0020739X.2020.1807069 


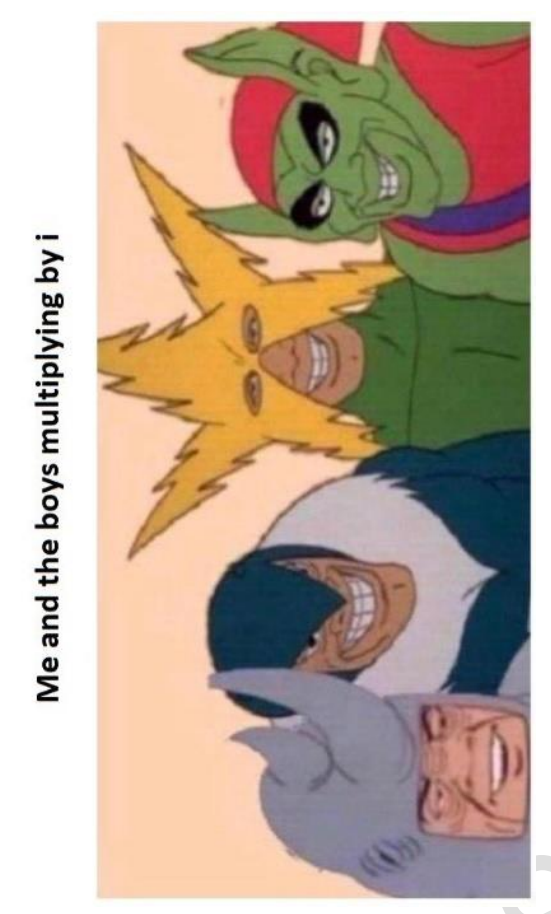

Figure 4. Me and the boys second mathematical mutation [source Facebook]

In the example described, a popular image becomes a meme changing in the hands of web users who reinterpret it, adding a personal humorous touch. The process suddenly turns towards specialized mathematical contents when the memetic narrative device is edited to encode a mathematical idea. This mutation is further followed by users, who consequently become involved in the construction of a new form of representation of mathematical ideas, different from all other known representations, such as diagrams, graphs, number lines, manipulatives or formulas (Goldin, 2014). Reconsidering this process, we can grasp the gist of what memes are: a type of visual entertainment in the form of an indefinitely editable narrative device, composed of an image and a text. In the networked Internet environment, a meme spreads from user to user with changes in the text and possibly in the image, maintaining an overall recognizability. Mathematical memes are a type of memes in which the textual part refers to a mathematical idea, that can be identified combining the information carried by the text with those carried by the image: in other words, a mathematical meme is a kind of riddle that can be decoded with the help of mathematics. The encoding/decoding mechanism 
mentioned above enlightens the educational potential of these objects for the learning of mathematics.

\section{Rationale and research questions}

Internet has produced a digital environment in which $21^{\text {st }}$-century students are immersed and where knowledge is easily accessible. In this culture, memes are recognized as building blocks (Milner, 2013; Marwick, 2013; Miltner, 2014; Shifman, 2014). Until now, they have been studied across different perspectives: digital culture (Stryker, 2011; Davison, 2012; Börzsei, 2013; Shifman, 2014; Danesi, 2019), genre studies (Wiggins \& Bowers, 2015), semiotics (Cannizzaro, 2016; Osterroth, 2018), rhetoric and affect (Huntington, 2013, 2017). Their significance in the online culture is so widely established that, recently, research efforts have been aimed at developing a new technology to make memes accessible for people with visual impairment (Gleason et al., 2019). However, memes are greatly understudied in educational research written in English: we have found examples in new literacy (Lankshear \& Knobel, 2003; Knobel \& Lankshear, 2005, 2007, 2018; Silva, 2016; Harvey \& Palese, 2018; Wells, 2018), racial discourse (Yoon, 2016) and visual literacy in language education (Romero \& Bobkina, 2017). Portuguese-speaking academia seems more open to integrating memes into educational settings: an updated survey of Portuguese educational literature on memes, referencing 17 studies on the subject, can be found in Santos and Carvalho's work (2019). In the field of mathematics education, apart from Bini and Robutti's (2019a, 2019b, 2019c) conference papers and Ward-Penny's work (2011) that focuses on pre-Internet mathematical memes, we have found only five studies on mathematical memes. One in Spanish (BeltránPellicer, 2016), three in Portuguese (Gonçalves \& Gonçalves, 2015; Gonçalves, 2016; Friske, 2018) and one in English (Benoit, 2018). Benoit looks into mathematical memes to study the perception of mathematics in popular culture. Beltrán-Pellicer (2016) and Friske (2018) describe their class-use with students and prospective teachers. In Gonçalves \& Gonçalves 
(2015) and Gonçalves (2016), beyond a categorization according to teaching aspects (such as theme or purpose) of 30 mathematical memes, no further clarification of the phenomenon of mathematical memes themselves is revealed.

All cited studies agree on the fact that memes can activate educational situations where some knowledge, e.g. mathematical, is learned by users. However, they achieve their findings by focusing on memes only, separated from their natural habitat. This approach leaves two significant aspects aside: the study of the connections between mathematical memes and their ecological cultural environment, and the study of the interactions they initiate within online communities. Mathematical memes are media: they represent, and therefore communicate, mathematical ideas. According to Jenkins and Gitelman, media are defined through a two-level model "on the first, a medium is a technology that enables communication; on the second, a medium is a set of associated 'protocols' or social and cultural practices that have grown up around that technology" (Gitelman, 2006 as cited in Jenkins, 2006, pp. 13-14). Referring to these two levels, we want to deepen our understanding of the phenomenon of mathematical memes as representations of mathematical ideas and investigate how it is shaped and how it is used within online communities. To be more specificsorting we ask:

- How can the phenomenon of mathematical memes be characterized as a representation of mathematical ideas within the Internet culture?

- How do mathematical memes activate and guide interactions among members of online communities?

These research questions are answered by investigating mathematical memes with a twofold theoretical lens: a memetic background, focused on characterizing mathematical memes as Internet artefacts; and a cultural background, dedicated to characterizing mathematical memes as cultural objects of the Web 2.0. Based on the innovative character of our research, we have entered the field with an ethnographical approach, deciding to collect mathematical memes and their threads of comments in social media communities. In the paper, we start our empirical 
investigation by mapping the field in order to identify appropriate data sources to study the phenomenon in relation to its online communities. Then we identify paradigmatic cases for an instrumental case study to reconstruct in detail how a community deals with the mathematical idea encoded in a meme. We finally discuss the results with respect to the original questions, providing a conceptualization of the phenomenon and reflect on the educational potential of mathematical memes for the teaching and learning of mathematics.

\section{Theoretical background}

\section{The memetic perspective: mathematical memes as Internet artefacts}

As a first step to understand mathematical memes, we address the fact that they are part of the general Internet phenomenon of memes, following a line of investigation aimed at eliciting what constituent elements of Internet memes occur in mathematical memes and how these elements are edited to encode a mathematical idea.

The first definition of memes as a contemporary Internet phenomenon is given by Davison (2012, p. 122): “an Internet meme is a piece of culture, typically a joke, which gains influence through online transmission". A more recent and detailed definition, frequently referred to in literature, is the online Oxford Dictionary entry ${ }^{1}$ (n.d. para. 2) where a meme is described as "an image, a video, a piece of text, etc. that is passed very quickly from one Internet user to another, often with slight changes that make it humorous". Memes are generally shared in social media platforms and dedicated websites (meme aggregators): these environments, identified in literature with the terms memesphere (Stryker, 2011) or memescape (Wiggins \& Bowers, 2015), are governed by collectively established and shared rules (Osterroth, 2018), and constitute the virtual and cultural habitat where Internet memes are created and consumed.

Although memes have become common ground in the Internet era, the term meme dates back to the mid 7's, when evolutionary biologist Dawkins derived it from the Greek word 
$\mu$ í $\mu \mu \alpha$, meaning imitation, to identify "a unit of culture that is passed from one generation to another and can be understood as the cultural equivalent of a gene [...] examples of memes are tunes, ideas, catch-phrases, clothes fashions, ways of making pots or of building arches" (Dawkins, 1976, p. 249). Merging the various definitions, we can say that Internet memes are comprised of the following elements: a digital image and/or video or text, a typically humorous nature, a very high changeability and spreadability (Jenkins, 2013), and a capacity of being a unit of culture. Due to their digital nature, Internet memes spread across space and cultures at an extremely faster pace than their offline ancestors, and have reached a massive worldwide diffusion (Figure 5, data collected by the first author).

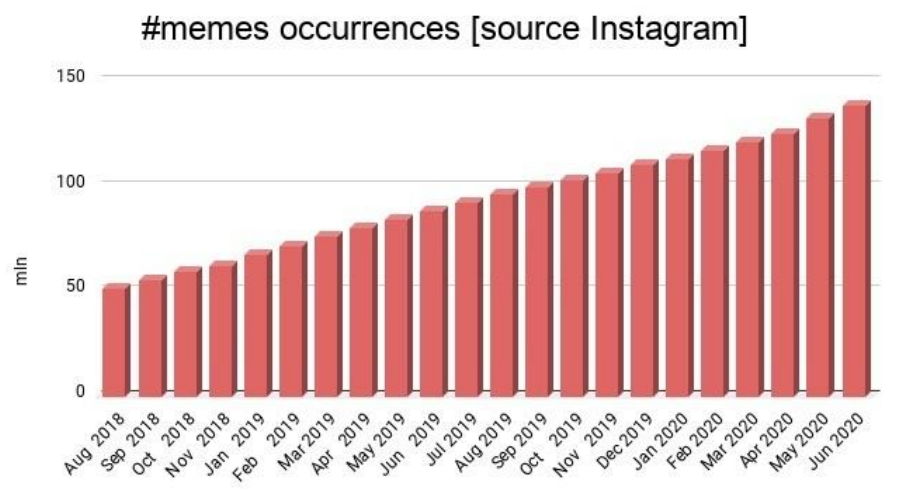

Figure 5. Diffusion of the hashtag \#memes in millions [source Instagram]

Artefacts corresponding to the hashtag \#memes belong to all categories listed in the dictionary definition: they can be images, videos or texts. In fact, Shifman (2014, pp. 99-117) classifies nine meme genres between video and image-based memes. Video-based memes in Shifman's classification are (1) "flash mobs", videos depicting strangers who gather in a public place to perform a particular act, (2) "lip-synch", videos in which a popular song or movie clip is dubbed with a user-created soundtrack, (3) "misheard lyrics", captioned videos with deliberately erroneous translations of spoken sounds, and (4) "recut trailers", reinterpreted movie trailers. Image-based memes are (5) "photo fads", staged photos in which the subject imitates a specific action, (6) "reaction photoshops", user-created images incorporating a 
specific recurring element, (7) "LOLCats", images of cats with misspelled captions, (8) "rage comics", amateur-looking comics with particularly expressive characters, and (9) "stock character macros" (now known as image macros), existing digital images wittily reinterpreted with superimposed captions. Image macros are by far the most diffused kind of meme, to the extent that, in a process of semantic narrowing (Wilkins, 1996), the term meme is now commonly used as a synonym for image macro, and the original wider meaning is almost forgotten.

Mathematical memes come also mostly in the form of image macros, so we focus on this genre of memes, exemplified by the Me and the boys opening example. In Figure 6 the relation between mathematical memes and other memetic artefacts is represented, showing a nearly nested structure.

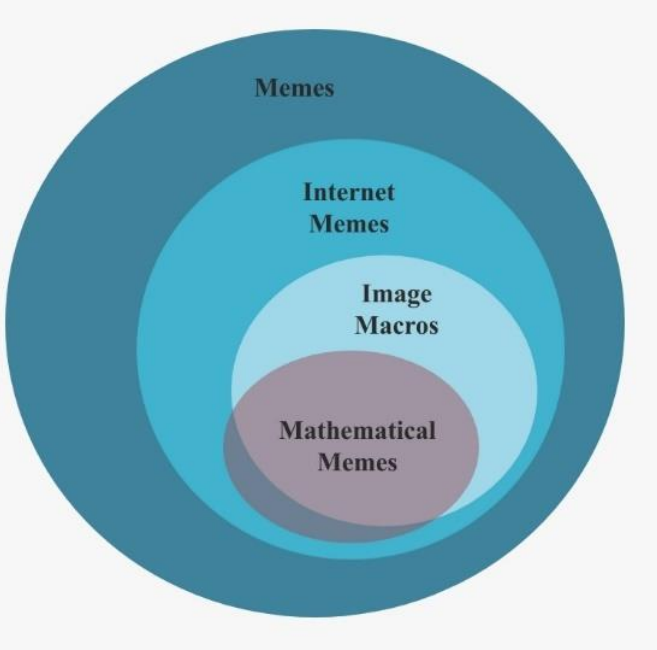

Figure 6. Embedding mathematical memes into the general phenomenon of memes

As we now take image macros as our core focus, we give a description of their constituent elements and of the process that originates them, based on literature (Davison, 2012; Shifman, 2014; Wiggins \& Bowers, 2015) and on the first author's two years' experience observing online communities dedicated to mathematical memes and collecting around 1000 mathematical memes. As already noted, memes are basically jokes made up of a pictorial and a textual part. The pictorial element is usually an eye-catching picture, which appeared on the 
web in a different context: it can be the portrait of a celebrity or a common person, a famous logo, a snapshot from a video or a comic strip, as in the Me and the boys example. The creator of the meme extracts it from its original context and encodes a new meaning in it, adding a coherent humorous caption and possibly editing the image, and uploads it to a sharing website. The meme, thus, begins its virtual roaming in the memesphere, where it can inspire new mutations. Some images prompt only a few personalisations, while others become established meme bases, acquiring names and codified meanings, with the initial figure clearly recognizable as a characteristic trait. Here is where the meme acquires its value as a unit of culture, where the image becomes able to transmit meanings for those who have the knowledge to read it. The cultural level achieved is confirmed by the circumstance that established memes and their meanings are categorized in the Know Your Meme website (www.knowyourmeme.com), an online meme encyclopaedia created and edited by volunteer contributors around the world. In a nutshell, the core characteristics of these memes are recognizability of the meme base and sharpness of the joke, attained with a right match of humour and subject knowledge. Capturing the meaning of the meme base and connecting it to the text allows to decode the meme, grasp the joke and laugh, as happens in the Me and the boys example.

Memes' constituent elements are maintained in mathematical memes, with the textual and pictorial part edited to convey a particular mathematical idea. This allows us to summarize the constituent elements in the following compositional structure. Mathematical memes are artefacts where a meme base and a mathematical idea are merged through a humorous/emotional link (Figure 7) that embodies the mathematical content in a rigorous sense. This merger creates a new kind of encoded representation of a mathematical idea that can be decoded only if the mathematics and the meme base are understood, and the mathematical meme is consequently interpreted through the lens of this understanding.

This is the Accepted Manuscript of an article published by Taylor \& Francis in International Journal of Mathematical Education in Science and Technology on 26 September 2020, available at https://www.tandfonline.com/doi/full/10.1080/0020739X.2020.1807069 


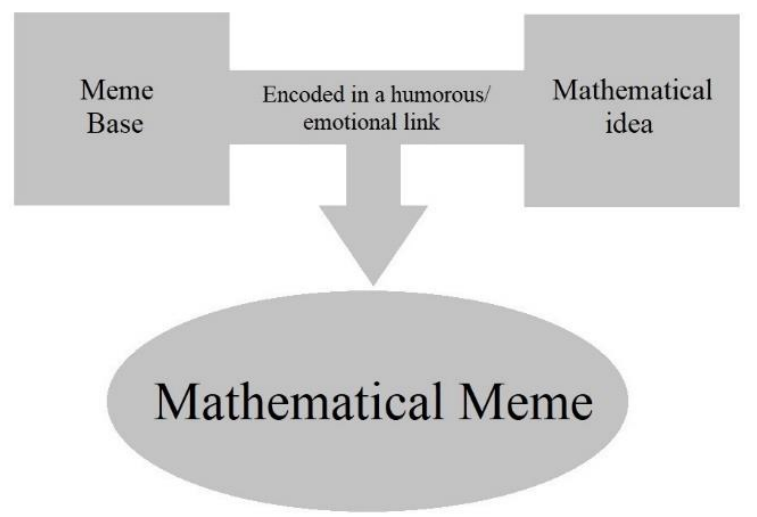

Figure 7. The compositional structure of a mathematical meme

To understand how these constituent elements are edited to encode a mathematical idea, we apply the compositional structure in Fig. 7 to some cases of popular mathematical memes, starting with the initial Me and the Boys examples.
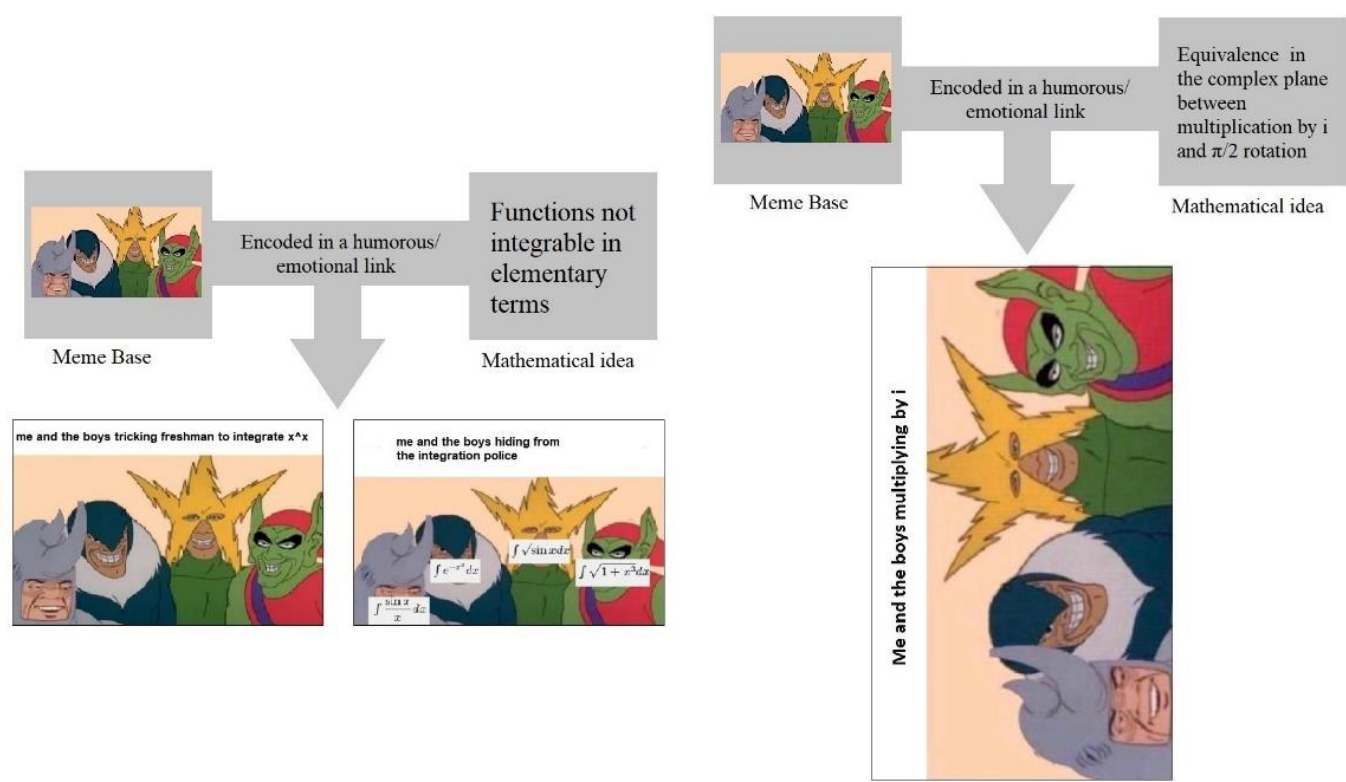

Figures 8(a) 8(b). Me and the boys mathematical memes [see Figures 3 and 4]

Both memes in Figure 8a use the metaphorical meaning of the Me and the boys meme base as shared school experiences to connect a goliardic feeling to the mathematical idea of functions that are not integrable in elementary terms. In the meme in Figure $8 b$ the conventional meaning is overruled, for the image is iconically used to encode the mathematical idea of the rotation in the complex plane, hinted by the caption. However, the link between the meme base

This is the Accepted Manuscript of an article published by Taylor \& Francis in International Journal of Mathematical Education in Science and Technology on 26 September 2020, available at https://www.tandfonline.com/doi/full/10.1080/0020739X.2020.1807069 
and the mathematical idea draws its humorous strength from the popularity of the original horizontal image.
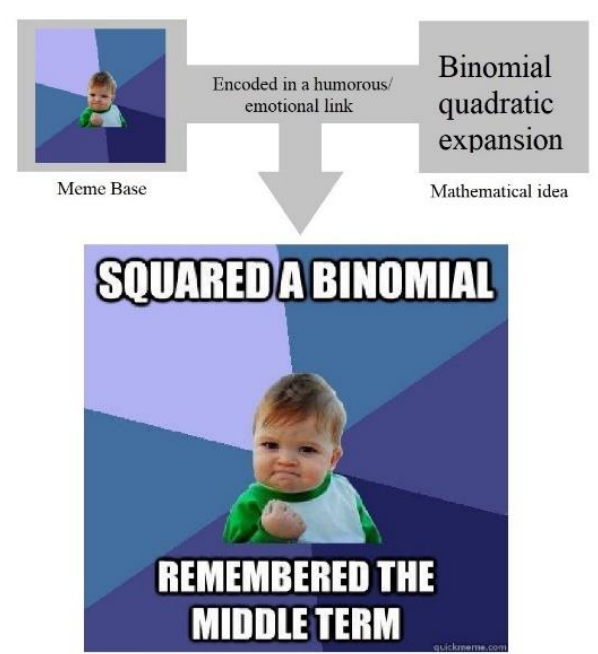

Figure 9. Success kid mathematical meme [source Facebook]

In the example in Figure 9, the metaphorical meaning of the Success kid meme base to boast about something good is used to connect a positive feeling to the correct computation of the binomial quadratic expansion. This meme encodes the mathematical idea in a didactical way, focusing on the recurring mistake of forgetting the middle term. The result is an artefact that can be decoded only if the viewer knows the binomial expansion, is aware that the middle term is often forgotten and thus can relate the mathematical message to the meme base metaphorical meaning.
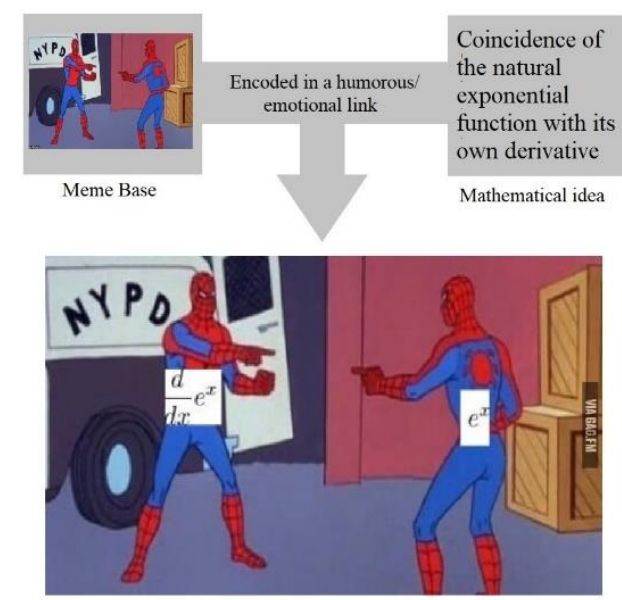

Figure 10. Spiderman pointing at Spiderman mathematical meme [source Reddit]

This is the Accepted Manuscript of an article published by Taylor \& Francis in International Journal of Mathematical Education in Science and Technology on 26 September 2020, available at https://www.tandfonline.com/doi/full/10.1080/0020739X.2020.1807069 
In the example in Figure 10 we see how the metaphorical meaning of the Spiderman pointing at Spiderman meme base, i.e. the meeting of two similar elements, is used to convey the mathematical idea of the coincidence between the exponential function and its derivative. In this case the meme base is used to encode part of the mathematical idea, namely the equal sign that links the two mathematical expressions.

Going back to the line of investigation at the beginning of this paragraph, the memetic theoretical background allows to understand that humour and emotions, spreadability and diffusion, and image macros structural and compositional rules are the constituent elements of Internet memes that occur in mathematical memes, and that, in mathematical memes, images are edited to encode mathematically rigorous effects (tangible or emotional) or elements of the mathematical idea hinted by the text.

\section{The cultural perspective: mathematical memes as Web 2.0 cultural objects}

As a second step to understand the phenomenon of mathematical memes, we address the fact that they are part of the culture that typify the Web 2.0, the development of the World Wide Web that emphasizes collaboration between users, social networking and user-generated content. This is done following a line of investigation aimed at eliciting what features of the Web 2.0 culture relate to the production and use of mathematical memes and how the perception of mathematical memes is shaped by these features.

The culture nurtured in the Web 2.0 environment is characterized by Jenkins as being participatory (2009) and convergent (2006, a term which has to be interpreted in a nonmathematical way). Participatory culture is typified by a "strong support for creating and sharing creations with others, [and] some type of informal mentorship whereby what is known by the most experienced is passed along to novices" (Jenkins, 2009, pp. 5-6, emphasis added). Building on Jenkins' idea, Bruns (2008) introduces the hybrid term produsage, a portmanteau of the words production and usage, to summarize the participatory environment nurtured by 
social software, whose protagonists not only use digital content, but also produce it, as happens for example with online encyclopaedias like Know Your Meme or Wikipedia.

In this environment, "Internet users seemed to have grasped [...] that the meme is the best concept to encapsulate some of the most fundamental aspects of the Internet in general, and of the so-called participatory or Web 2.0 culture" (Shifman, 2014, p. 18, emphasis in original) because they "harness the participatory potential of the Internet and typify modern popular culture" (Marwick, 2013, p. 13). So, the participatory culture inspires Internet users to create memes in general (Wiggins \& Bowers, 2015) and mathematical memes in particular. It fuels the creative activity, which reveals itself both in the making of the mathematical meme and in the interaction around it, through which people with good math skills offer their “informal mentorship" (Jenkins, 2009, p. 6) to less skilled individuals. The qualifying value of participation in the Web 2.0 ecosystem explains also the role that memes have in this culture. In an environment where users "care what other people think about what they have created" (p. 6), memes are exchanged as "passcodes" (Schmidt, 2014, 00:08:55) to regulate the entrance to the memesphere or the "status in the community" (Stryker, 2011, p. 76).

The first author's observation of online communities dedicated to mathematical memes, revealed that these communities form a sub-region of the memesphere, whose citizens are proficient in memes and mathematics. Symbolic admission is granted only by sharing OC (original content), i.e. mathematical memes not copied from elsewhere, that have to be appropriate at both memetic and mathematical level. We take as an example the meme in Figure 11 and an excerpt of its comments ${ }^{2}$ :

This is the Accepted Manuscript of an article published by Taylor \& Francis in International Journal of Mathematical Education in Science and Technology on 26 September 2020, available at https://www.tandfonline.com/doi/full/10.1080/0020739X.2020.1807069 


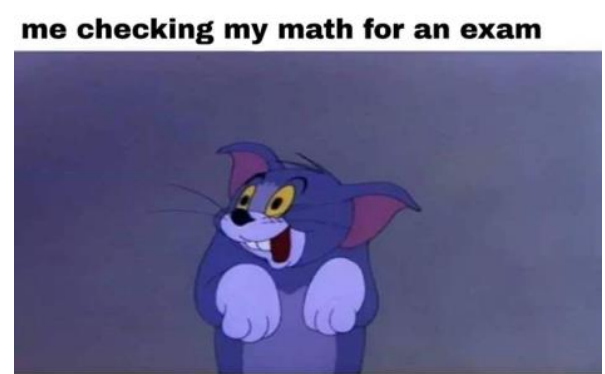

\section{me checking my math for a math meme page}

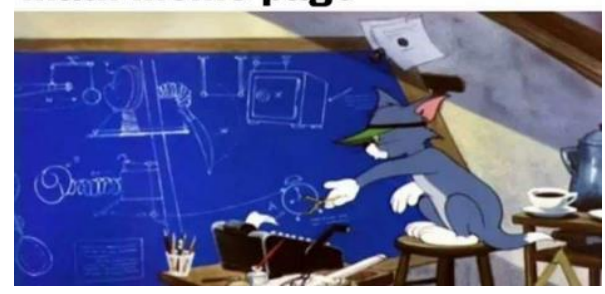

Figure 11. Checking the mathematics behind a meme [source Facebook]

1-C1: if your math is wrong in a meme, the repercussions are a lot more severe lol $[\ldots]$

2-C2: Well that's because the teacher is a single person who will ridicule you in private if you're wrong. Lol. I haven't shared anything to this group because the small pool of things I could come up with have already been done

3-C3: It's only right. You're risking your good name throwing math memes out there

This is a meme about mathematical memes (i.e. a meta-meme), that is taken as a source to gain information about the cultural practices (in the sense of Gitelman, 2006) grown up around mathematical memes. It describes the users' contrasting attitudes with respect to school mathematics and meme mathematics. Produsers of mathematical memes show a responsible attitude in checking their mathematical content, as opposed to a more naïve attitude shown towards school mathematics. Comments indicate the reasons why this checking has to be thorough (\#1), that the content has to be original (\#2), and that mathematical memes are perceived as personal identifiers in the community, acting as passcodes or as status qualifiers (\#3). This example is one of many from which we can infer that mathematical memes are perceived as qualifying proofs of produsers' mathematical knowledge, because memes in these 
communities are publicly scrutinized by a cultured, merciless and potentially worldwide audience.

Besides participation, the second typifying characteristic of the Web 2.0 culture is convergence. Convergence is not simply the wide availability of information funnelled in a single device, but is "a cultural shift [in which] consumers are encouraged to seek out new information and make connections among dispersed media" (Jenkins, 2006, p. 3). In a convergent perspective, academic and popular culture are perceived as a continuum. For example, a recent discovery in number theory has been inspired by an episode of the popular TV series The Big Bang Theory (Pomerance \& Spicer, 2019), and an anonymous post on the social platform 4chan has given an essential contribution in solving a 25 -year-old problem in combinatorics (Anonymous 4chan Poster et al., 2018). In the memesphere, convergence is "a central pattern" (Danesi, 2019, p. 57): this implies, among other things, that the traditional boundaries of education are challenged. Thus, Web 2.0 users are ready to learn even if they are not at school (Thomas \& Seely Brown, 2011; Ito et al., 2013), in a process of "collective meaning-making $[\ldots]$ within the brains of individual consumers and through their social interactions with others" (Jenkins, 2006, pp. 3-4, emphasis added). Convergence describes how mathematical memes act as "cultural activators, setting into motion their decipherment, speculation, and elaboration" (p. 95). They spark a process of collective meaning-making, providing opportunities for non-curricular learning experiences, a practice which is widely confirmed by evidences shared on the web. In Figure 12 we see two meta-memes expressing appreciation for the use of mathematical memes to support the understanding of mathematical concepts (12a) and to foster engagement (12b).

This is the Accepted Manuscript of an article published by Taylor \& Francis in International Journal of Mathematical Education in Science and Technology on 26 September 2020, available at https://www.tandfonline.com/doi/full/10.1080/0020739X.2020.1807069 

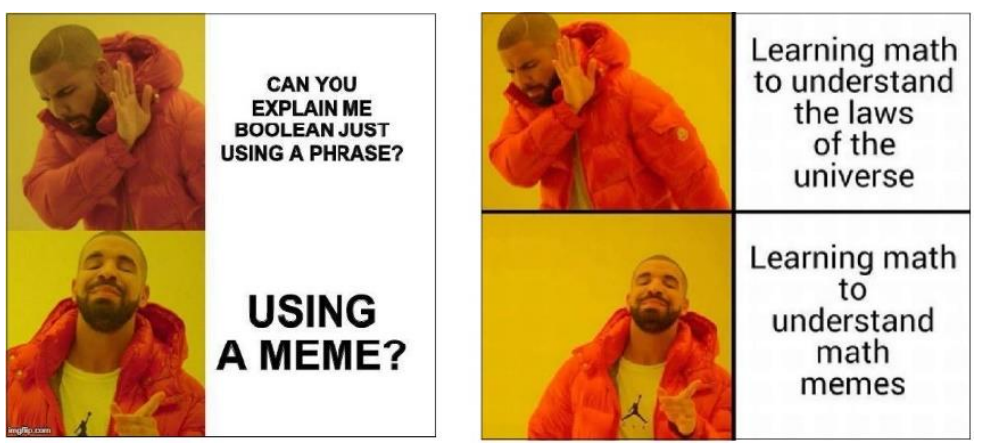

Figures 12(a) 12(b). Mathematical memes as learning objects

However, the meta-meme in Figure 13 shows that mathematical memes produsers are also aware that, to build proper mathematical knowledge non-curricular, meme-induced learning is not enough, but it has to be put together with curricular learning, in a truly convergent perspective where "old and new media collide" (p. 2).

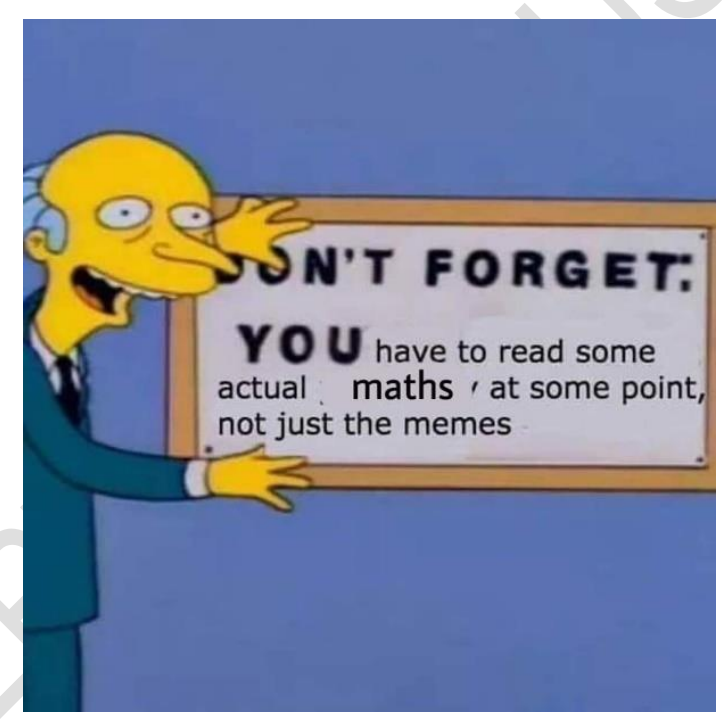

Figure 13. Don't forget to read some actual maths [source Facebook]

To sum up, the cultural theoretical background provides evidence to characterize mathematical memes as cultural objects, showing that participatory culture inspires the production of mathematical memes and shape their perception as membership identifiers, and that convergence culture inspires ways of using them as learning opportunities.

This is the Accepted Manuscript of an article published by Taylor \& Francis in International Journal of Mathematical Education in Science and Technology on 26 September 2020, available at https://www.tandfonline.com/doi/full/10.1080/0020739X.2020.1807069 


\section{Methodology and methods}

Based on the theoretical background, we were able to characterize mathematical memes as memetic artefacts encoding mathematical ideas, and as cultural objects in dedicated participatory and convergent online communities. These characterizations give some important information to start building up our answers to the research questions. What is still missing is a characterization of mathematical memes as representations of mathematical ideas and a deeper investigation of how they activate and guide interactions within the community. Since such a representation not only differs from all usual mathematical representations but is also in constant change in the mathematical memesphere, it can only be characterized from inside the meme community, for example analysing the meme's decoding process in the situated interactions among its members.

To address the missing information, we have approached the field ethnographically (Eisenhart, 1988; Harwati, 2019), considering practices as cultural habits shown and reestablished in the interaction among the members of the community (Gitelman, 2006). This ethnographic approach is chosen because it is aligned with our aim to investigate "what people's opinions are about a particular phenomenon occurred in their social context and what their action is". (Harwati, 2019, p. 152). The study began in February 2018 and is still in progress. It is conducted by participant observation of the first author being a read-only (a lurker in the Internet jargon) member of the communities without interacting with them. This role allowed the first author to become "part of the situation being studied in order to be able to feel the way people do in that situation" (p. 152), taking care not to perturb the environment while gathering data.

Data collected in the ethnographic research are chronological field notes, memes (constituting a meme pool) and their threads of comments (constituting a comment pool). Focusing on the comment pool, we reconstruct the interaction activated by the memes from 
inside the observed communities, considering the meaning-making processes. Because of the novelty of our topic, an instrumental case study that aims at theorizing through comparing cases is an appropriate approach (see Grandy, 2010), coherently combined with the ethnographic approach (Harwati, 2019). This case study follows the principle of comparison between two contrasting empirical cases, which represent polar types of mathematical memes, one being mathematically right and the other mathematically wrong. Data are analysed based on the tools provided by the theoretical background. The final step is theorizing the results with respect to the original aim of reaching a conceptualization of the phenomenon of mathematical memes. Since our study addresses an under-researched field of a fluid nature with a huge amount of available data sources on the web, our first step is to systematically map the field to identify appropriate data sources that could provide paradigmatic cases to investigate the community from the inside.

\section{Mapping the field and identifying appropriate data sources}

Memes are everywhere on the web, from blogs to meme aggregator websites and social media, but mathematical memes are shared mainly in social media websites. Therefore, to organize the research, we referred to the shared methodologies of qualitative research in social media as exposed by the Social Media Research Group (2016), the SAGE Handbook of Social Media Research Methods (Sloan \& Quan-Haase, 2016) and, in particular, to Hand's work onimpairment researching images in social media, included in the latter. According to Hand (2016), the primary methodological issue in investigating images in social media is due to the large amount of available data, which necessarily implies a selection that will affect the research and therefore must be made knowingly. This selection is conducted beginning with websites, funnelling towards particular communities as data sources: Choices were made applying combined criteria of popularity and relevance for the research as described below.

This is the Accepted Manuscript of an article published by Taylor \& Francis in International Journal of Mathematical Education in Science and Technology on 26 September 2020, available at https://www.tandfonline.com/doi/full/10.1080/0020739X.2020.1807069 
Within social media websites, the choice fell on Reddit (www.reddit.com), Facebook (www.facebook.com) and Instagram (www.instagram.com). Reddit (355 million users) was chosen for its relevance for the meme culture, being the commonly acknowledged birthplace of most memes (as happened to the Me and the boys example in the opening section). Facebook (2.26 billion users) and Instagram (1 billion users) were chosen for their popularity, being respectively first and second in the global social networks ranking (Statista $\left.{ }^{3}, 2019\right)$.

\section{Selecting communities}

In social media websites, we looked for active (i.e. sharing new content at least weekly) communities interested in mathematics and memes, using both the intern search engines with keywords meme+mathematics or meme+math/maths and the similar pages suggestion option. Among them, the second level of selection was again made according to popularity, based on the number of followers, expected to imply deeper, wider and more meaningful interactions. Thus, communities with more than 10,000 (10k) followers were chosen (Table 1).

Table 1. Observed communities ordered according to the number of followers (June 2020)

\begin{tabular}{|c|c|c|c|c|c|}
\hline \multicolumn{2}{|c|}{ Reddit } & \multicolumn{2}{|c|}{ Instagram } & \multicolumn{2}{|l|}{ Facebook } \\
\hline r/dankmemes & 3.7million & $\begin{array}{l}\text { @ bad science } \\
\text { jokes }\end{array}$ & $388 \mathrm{k}$ & Educational Memes & $597 \mathrm{k}$ \\
\hline $\mathrm{r} / \mathrm{math}$ & 1.2million & $\begin{array}{l}\text { @juicy } \\
\text { mathematical } \\
\text { memes }\end{array}$ & $128 \mathrm{k}$ & $\begin{array}{l}\text { Mathematical } \\
\text { Mathematics Memes } \\
\text { [group] }\end{array}$ & $226 \mathrm{k}$ \\
\hline r/theydidthemath & $601 \mathrm{k}$ & $\begin{array}{l}@ \text { meme for } \\
\text { mathematicians }\end{array}$ & $113 \mathrm{k}$ & I love Mathematics 2.0 & $110 \mathrm{k}$ \\
\hline r/mathmemes & $82.6 \mathrm{k}$ & @mathsforyou & $62.6 \mathrm{k}$ & $\begin{array}{l}\text { L'Agorà Del } \\
\text { Superuovo }\end{array}$ & $97.6 \mathrm{k}$ \\
\hline r/physicsmemes & $77 \mathrm{k}$ & @ maths.meme & $58.2 \mathrm{k}$ & Math Memes & $72 \mathrm{k}$ \\
\hline r/mathpics & $21.4 \mathrm{k}$ & $\begin{array}{l}\text { @memes } \\
\text { educational }\end{array}$ & $46.6 \mathrm{k}$ & $\begin{array}{l}\text { Matematica del } \\
\text { Suicidio }\end{array}$ & $30 \mathrm{k}$ \\
\hline & & $\begin{array}{l}\text { @ mathematical } \\
\text { jokes }\end{array}$ & $27.6 \mathrm{k}$ & Matemáticas y Café & $30 \mathrm{k}$ \\
\hline
\end{tabular}

This is the Accepted Manuscript of an article published by Taylor \& Francis in International Journal of Mathematical Education in Science and Technology on 26 September 2020, available at https://www.tandfonline.com/doi/full/10.1080/0020739X.2020.1807069 


\begin{tabular}{|l|l|l|l|l|l|}
\hline & $\begin{array}{l}\text { @ puremaths } \\
\text { memes }\end{array}$ & $22.8 \mathrm{k}$ & $\begin{array}{l}\text { >implying we can } \\
\text { discuss mathematics }\end{array}$ & $26 \mathrm{k}$ \\
\hline & @calculuscious & $21 \mathrm{k}$ & $\begin{array}{l}\text { The Name Of This } \\
\text { Group Is Left As An } \\
\text { Exercise For Its } \\
\text { Members }\end{array}$ & $12 \mathrm{k}$ \\
\hline
\end{tabular}

\section{Selecting data}

Communities in Table 1 were followed daily by the first author to collect data for the research.

Considering the prospective idea of using the results of this research to inform teaching in school, we selected mathematical memes encoding mathematical ideas on $8^{\text {th }}$ to $13^{\text {th }}$ grade mathematical topics according to the Italian national curriculum ${ }^{4}$, and meta-memes, i.e. memes about mathematical memes. Memes adhering to these criteria were downloaded and archived using a double tagging criterium (meme base name + brief math reference). In the period of observation (February 2018-current) this process produced a meme pool of around 1400 items, filtering reposts. This meme pool was complemented by a comment pool of saved active links connected to the first author's personal accounts on the three websites to follow real-time comments engagement. Occasionally these communities share other image-based humorous digital objects addressing mathematical themes, like memes dealing with emotions connected to doing mathematics and mathematical cartoons. These other objects were also inspected to gather information for comparison that could contribute in characterizing mathematical memes.

\section{Selecting cases}

As noted in the participant observation and described by Jenkins (2006), mathematical memes communities are coherent in the way they interact with memes. Therefore, our selected cases are present not for themselves but as representative characteristics of a class, in a sense echoing that of Balacheff's "generic examples" (1988, p. 57). Further, there is no theoretical knowledge about the nature of this kind of interaction in the context of mathematical memes communities. 
In order to disclose such theoretical knowledge we, therefore, have chosen the instrumental case study approach built on the "particularly important theoretical sampling strategy" (Eisenhardt \& Graebner, 2007, p. 27) of polar types, "in which a researcher samples extreme [...] cases in order to more easily observe contrasting patterns in the data", [relying of the fact that] this sampling leads to very clear pattern recognition of the central constructs, relationships, and logic of the focal phenomenon" (p. 27, emphasis added).

Communities usually share correct mathematical memes, while wrong memes are extremely rare. For that reason, we choose a mathematically correct and a mathematically wrong meme as the two extreme polar cases in our sampling strategy.

The choice of the environment of the polar cases was based on a quantitative criterion of popularity, i.e. the number of followers. Selected cases were chosen from Facebook, confirmed as the most popular social media among teens (13-17 y.o.) with 113 million users (Hootsuite We are Social Global Digital Report ${ }^{5}$, 2019; Edison Research, The Infinite Dial ${ }^{6}$, 2019). Within Facebook, we chose the most popular among the communities in Table 1: Educational Memes (597k users) and Mathematical Mathematics Memes (226k users). Among mathematical memes shared within these communities, we applied a qualitative criterium of choice, selecting the two memes among those where mathematics is deeply used, a characteristic expected to imply richer threads of comments and where highly relevant aspects are discussed, embracing Pettigrew's suggestion recalled by Eisenhardt (1989) that "if the phenomena to be observed is to be contained within a single or relatively small number of cases, then choose cases where the progress is transparently observable" (Pettigrew, 1988/1990, p. 275). In particular, our memes stood out because they dealt with two key issues for the teaching and learning of mathematics: the ability to identify circular arguments (Freudenthal, 1971; Hanna \& de Villiers, 2008) in the correct meme, and the misconceptions that could arise from the polysemy of mathematical symbols (Durkin \& Shire, 1991; Gray \& Tall, 1994; Priss, 2018) in the wrong one. We excluded 
a quantitative selection centred on the number of likes or comments because not fitting with the qualitative criterium of finding memes with deep mathematical content. The selection was carried out using a sorting criterion, to identify the two polar types, so that the emerging characterization is expected to be well grounded in their comparison (Eisenhardt, 1989; Eisenhardt \& Graebner, 2007).

\section{Analysing data}

Data in the meme and comment pools have been explored with an ethnographical attitude, taking as a unit of analysis the memes referring to their threads of comments. Mathematical memes were taken as a source to gain information about the interaction with the mathematical idea represented in the meme, and meta-memes were taken as a source to gain information about the cultural value of mathematical memes and of the related interaction inside the community.

In the empirical case study, theoretical concepts previously provided in the paper are merged in the analyses. In the first step, the encoding of the mathematical idea in each case is shown according to the compositional structure presented in Figure 7. In the second step, a sequential analysis of the thread of comments is conducted, following Jenkins's (2009) idea that the interaction in a community is a collective process where each contribution is related to the others. In the analysis, the process of meaning-making is reconstructed following the interactive threads of comments, where each comment is taken as an interpretation of previous comments and of the meme itself. Comments convey two levels of information: an explicit information, carried by the text openly expressing something, and an implicit information, carried by the way the comments are articulated, conveying information about the commenters themselves, their relationship with others and with the meme. These two levels of information are traced through the excerpts by re-interpreting comments in a turn-by-turn-analysis (Jungwirth, 2003).

This is the Accepted Manuscript of an article published by Taylor \& Francis in International Journal of Mathematical Education in Science and Technology on 26 September 2020, available at https://www.tandfonline.com/doi/full/10.1080/0020739X.2020.1807069 
We begin with a case whose mathematical content is correct (and recognized as such by the commenters), and then we analyse the mathematically incorrect case. As the culture in the community is re-shaped in the interaction around the mathematical meme, the cultural codes participatory and convergence are added in the analyses when evidenced. The analyses with the coded excerpts are then used to identify and synthesize the emergent mathematical themes. Separate analyses of each of the two polar types are subsequently compared and contrasted to answer the research questions. This will show how the meme drives the interaction and how the interaction keeps going while decoding the mathematical idea hereby encoded.

Complying with the ethical principles of social media research (Social Media Research Group, 2016), we do not include nor analyse produsers' personal information, replacing identifiers in all quoted excerpts $(\mathrm{A}=$ author of the mathematical meme, $\mathrm{C} 1 \mathrm{C} 2 \mathrm{C} 3 \ldots=$ commenters) and adopting an inclusive and bias-free language in our analysis. All comments are unredacted and originally in English. To follow the development of the interaction across time, the excerpts are reported in chronological order with the timestamp of the meme and of the first and last comment, and the indication, whenever present, of who is replying to who. If needed, slang terms are interpreted using the Urban Dictionary website (www.urbandictionary.com).

\section{Analyses and results}

To understand the phenomenon of mathematical memes with respect to their use as representations of mathematical ideas inside the community and investigate how they activate and guide interactions among members, we first summarize the results of our participant observation while collecting the meme and comment pools.

This is the Accepted Manuscript of an article published by Taylor \& Francis in International Journal of Mathematical Education in Science and Technology on 26 September 2020, available at https://www.tandfonline.com/doi/full/10.1080/0020739X.2020.1807069 


\section{Participant observation: memes and mathematical ideas}

The ethnographic research, documented by the ethnographic representative in the author group with chronological notes, has provided a data pool organised for the specific purpose of this part. From this data pool, we have extracted information about the practices around mathematical memes in the inspected communities.

Our observation revealed that almost all mathematical memes are followed, in the same social media page, by threads of comments where the meme's mathematical content is discussed by the meme's author and other users. It revealed also that the practice of exchanging mathematical comments is specific of mathematical memes: in fact, in the case of memes about emotions connected to doing mathematics (Figure 14a) there are usually no mathematical comments, but just common emojis or friends tagging. The same applies to cartoons about mathematics (Figure 14b) which are different digital objects having, sometimes, a proper mathematical content.
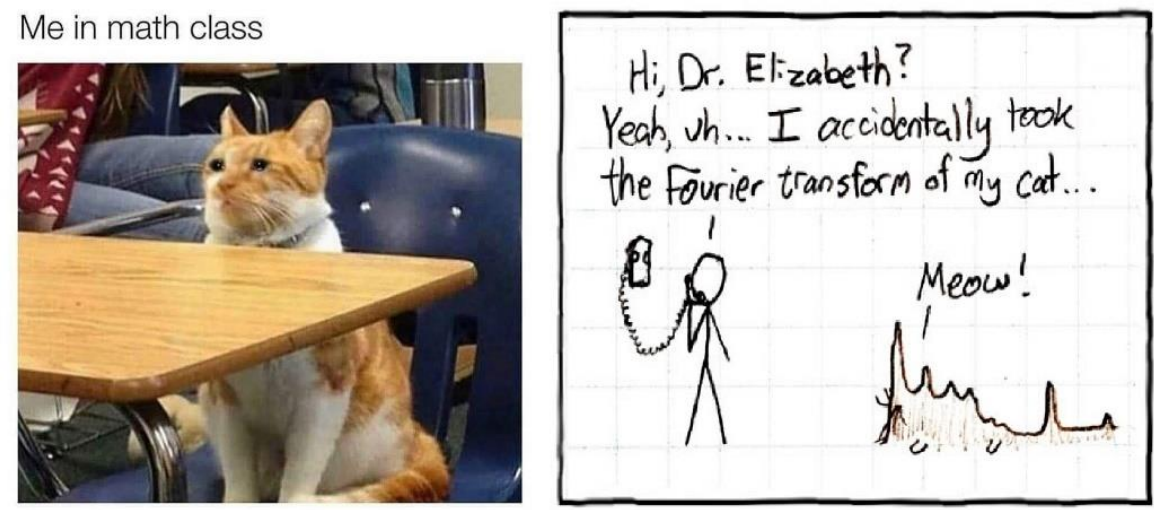

Figures 14(a) 14(b). Emotional memes and cartoons [sources Facebook and xkcd.com]

Thus, we can say that, among image-based humorous digital objects exchanged within the observed communities, threads of explicated mathematics stand out as a characterizing practice of the interaction with mathematical memes as representations of mathematical ideas.

The importance of mathematical comments in the community is confirmed by the high value given to this habit, as shown for example in the meta-meme in Figure 15.

This is the Accepted Manuscript of an article published by Taylor \& Francis in International Journal of Mathematical Education in Science and Technology on 26 September 2020, available at https://www.tandfonline.com/doi/full/10.1080/0020739X.2020.1807069 
When you post a math meme

and people comment about

the theory behind it

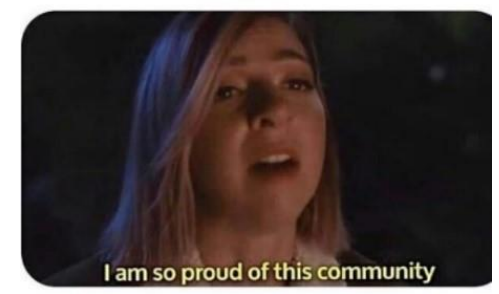

Figure 15. The importance of mathematical comments [source Facebook]

The observation of these interactions proves that threads of explicated mathematics are not simply openings for more educated members of the community to show off some knowledge. In fact, they allow the collective meaning-making of the mathematical idea encoded in the meme to take place. This is clearly acknowledged in the comments to the meta-meme in Figure 16.

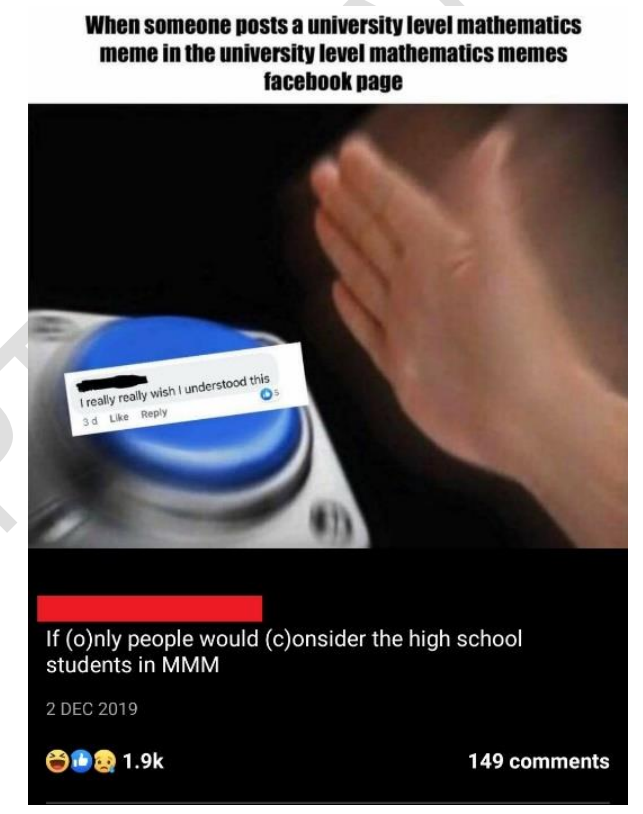

Figure 16. The importance of understanding mathematical memes [source Facebook]

This meme, posted in the Mathematical Mathematics Memes (MMM) page, addresses the issue of high school students' understanding of university level mathematical memes. The image of a hand moving fast towards a blue button is a popular meme base used to symbolise situations that trigger impulsive reactions. In this case the triggering situation is described by

This is the Accepted Manuscript of an article published by Taylor \& Francis in International Journal of Mathematical Education in Science and Technology on 26 September 2020, available at https://www.tandfonline.com/doi/full/10.1080/0020739X.2020.1807069 
the top text "When someone posts a university level mathematics meme in the university level mathematics meme facebook page" and the impulsive reaction is represented by the caption superimposed on the button "I really really wish I understood this". The author's note accompanying the meme "if (o)nly people would (c)onsider the high school students in MMM" and the number of likes $(1,9 \mathrm{k})$ tell us how much this feeling is experienced within the community, while the following excerpt from the 149 comments gives us insight into how the community relies on the threads of explicated mathematics to overcome these difficulties.

1-C1: Every time I've seen someone actually explain the mathematics behind a meme, it's been a great experience. ... [I] feel like going and learning more. Thank you to those wonderful mathmemeaticians who help others appreciate the joy of glimpsing new realms of mathematics.

$[\ldots]$

2-C2: I think this group is the very reason why i am even more interested in mathematics than $\mathrm{i}$ was before, even though i dont understand more than half of the stuff here...i $\mathrm{m}$ still learning and its really fun!

Here we see that explaining the mathematics behind a meme is accredited to activate the learning mechanisms (\#1) and that mathematical memes are recognized as resources to foster learning and interest in mathematics (\#2).

This characterizing practice is connected to both features of the Web 2.0 culture: it is participatory in the sense that it gives commenters the opportunity to contribute offering the characterizing informal mentorship, and it is convergent because the interplay between mathematical memes and comments allow the collective meaning-making to happen. Indeed, these communities operate as spontaneous communities of practice (Wenger, 1998), and build group meanings of mathematical concepts, acting as a "sphere[s] of practice" where “mathematical meanings are constructed" (Kilpatrick et al., 2005, p. 10).

The educational value of mathematical memes and their threads of mathematical comments is not only recognized by members of the community, but it may also be the reason 
for the very existence of the community. This is the case of MEME4000W, two twin mathematical memes pages created by graduate students on Facebook and Instagram, to teach mathematical concepts using memes as a medium. The following interview excerpt illustrates the origin of the project:

At the start of last year, I joined a mathematics meme group and realized that I learn so much from the interactions on the group, through the memes and the comments [emphasis added]. I wanted to share this experience with others and show them that maths isn't as threatening as people make it out to be: It can be experienced in a very fun and conducive environment. (founder of the pages, interviewed by the first author via chat, April 2019).

All these evidences indicate that threads of explicit mathematical comments connected to mathematical memes are exactly the loci where the characteristics of mathematical memes as representations of mathematical ideas become evident, and where the educational potentialities of these objects can be observed. In the next paragraph we deepen our understanding of the phenomenon by analysing the interaction in two contrasting cases selected according to the criteria explained in the methodology section.

\section{Instrumental case study: Threads of comments on mathematical memes}

\section{Case 1: the correct meme}

- Meme base name: Mega Wrong!

- Meme base use: stigmatize situations where something significantly wrong occurs

- Source: Facebook Total comments: 96

- Topic: Calculus

- Subtopic: Circular reasoning, Limits, Derivatives proofs, L'Hôpital's rule

- Publication year: 2019

This is the Accepted Manuscript of an article published by Taylor \& Francis in International Journal of Mathematical Education in Science and Technology on 26 September 2020, available at https://www.tandfonline.com/doi/full/10.1080/0020739X.2020.1807069 

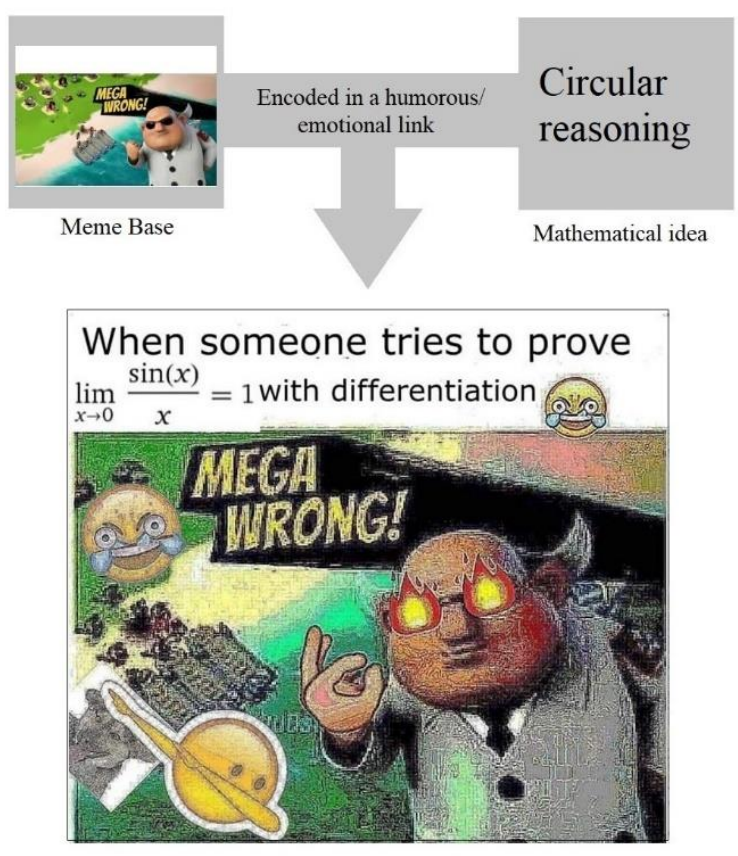

Figure 17. Case 1: the memetic analysis

Contextual description: The meme in this example (Figure 17) is used to label as Mega Wrong the proof of the indicated limit using differentiation (i.e. L'Hôpital's rule). The proof is considered Mega Wrong because it is circular, involving a logical fallacy that occurs if we assume that the derivative of the sine function is obtained using the result of the $\lim _{x \rightarrow 0} \frac{\sin x}{x}$, which is the usual development of the topic in high school. This same procedure would be logically sound if, for example, we accept power-series definitions for trigonometric functions, and obtain the derivative of the sine function from these premises. This knowledge is mastered and disseminated by the author of the meme and by several commenters, as will be shown in the analysis. We chose key parts of the exchange taking a large section from the beginning where the engagement is established. We are taking further parts following the same mathematical topic. The selection is also made according to indicators related to the analysis perspective. The development of the comments goes in various directions, several proofs are offered, only one is included in the analysed excerpt (Table 2).

Table 2. Case 1 - the cultural analysis

This is the Accepted Manuscript of an article published by Taylor \& Francis in International Journal of Mathematical Education in Science and Technology on 26 September 2020, available at https://www.tandfonline.com/doi/full/10.1080/0020739X.2020.1807069 


\begin{tabular}{|c|c|c|c|c|}
\hline Comments & $\begin{array}{l}\text { Explicit } \\
\text { information }\end{array}$ & Implicit information & $\begin{array}{l}\text { Environmental } \\
\text { culture }\end{array}$ & $\begin{array}{l}\text { Emerging } \\
\text { mathematical } \\
\text { themes }\end{array}$ \\
\hline $\begin{array}{l}\text { 1-C1: [Day 1; } \\
\text { 16:29] How is } \\
\text { lhopitals not } \\
\text { correct }\end{array}$ & $\begin{array}{l}\text { Asks for reasoning } \\
\text { (need) about what } \\
\text { is labelled as "mega } \\
\text { wrong" in the } \\
\text { meme }\end{array}$ & $\begin{array}{l}\text { How means "how } \\
\text { come", an informal } \\
\text { way to ask about the } \\
\text { reason, (need for } \\
\text { reason). } \\
\text { C1 shows knowledge } \\
\text { (recognizing the limit } \\
\text { and that differentiation } \\
\text { refers to L'Hôpital's } \\
\text { rule); C1 is open for } \\
\text { broadening knowledge } \\
\text { (why this procedure is } \\
\text { incorrect) }\end{array}$ & $\begin{array}{l}\mathrm{C} 1 \text { addresses } \\
\text { the community } \\
\text { as a knowledge } \\
\text { holder for the } \\
\text { meaning- } \\
\text { making } \\
\text { (convergence } \\
\text { culture) }\end{array}$ & \multirow{5}{*}{$\begin{array}{l}\text { Why using } \\
\text { differentiation } \\
\text { to solve the } \\
\text { limit is } \\
\text { incorrect }\end{array}$} \\
\hline \multicolumn{5}{|l|}{$[\ldots]$} \\
\hline $\begin{array}{l}\text { 2-C3: That } \\
\text { would be a } \\
\text { circular } \\
\text { argument }\end{array}$ & $\begin{array}{l}\text { Gives a key word } \\
\text { that it is "mega } \\
\text { wrong" because of } \\
\text { a logical fallacy }\end{array}$ & $\begin{array}{l}\text { C2 leaves deeper } \\
\text { reasons unexplained, } \\
\text { acknowledges the } \\
\text { expertise shown by } \mathrm{C} 1\end{array}$ & $\begin{array}{l}\text { Informal } \\
\text { mentorship } \\
\text { (participatory } \\
\text { culture) }\end{array}$ & \\
\hline $\begin{array}{l}\text { 3-C3: um } \\
\text { why? }\end{array}$ & $\begin{array}{l}\text { Asks for reasons } \\
\text { why (need for } \\
\text { reasons) }\end{array}$ & $\begin{array}{l}\text { The expression "um" } \\
\text { indicates uneasiness, } \\
\text { probably due to the } \\
\text { lack of reason in C2's } \\
\text { answer, thus C3 } \\
\text { explicitly asks "why" }\end{array}$ & $\begin{array}{l}\text { C3 needs help } \\
\text { from the } \\
\text { community for } \\
\text { the meaning } \\
\text { making } \\
\text { (convergence } \\
\text { culture) }\end{array}$ & \\
\hline $\begin{array}{l}\text { 4-C4: You } \\
\text { usually use } \\
\sin (x) / x \rightarrow 1 \text { to } \\
\text { prove } \sin ^{\prime}=\cos \end{array}$ & $\begin{array}{l}\text { Provides a missing } \\
\text { reason, a brief } \\
\text { explanation (reacts } \\
\text { to the need) about } \\
\text { the circularity }\end{array}$ & $\begin{array}{l}\text { C4 shows experience } \\
\text { and assumes C3 } \\
\text { knows that applying } \\
\text { L'Hôpital's rule to the } \\
\text { limit means using the } \\
\text { derivative of y=sinx, } \\
\text { recognizes sin' as the } \\
\text { derivative }\end{array}$ & $\begin{array}{l}\text { C4 explains, } \\
\text { hence, practices } \\
\text { informal } \\
\text { mentorship } \\
\text { (participatory } \\
\text { culture) }\end{array}$ & \\
\hline $\begin{array}{l}\text { 5-C3: Oh, } \\
\text { right. Yeah } \\
\text { that }\end{array}$ & Acknowledgment & $\begin{array}{l}\text { The acknowledgement } \\
\text { without further } \\
\text { questions indicates } \\
\text { that C3 was already } \\
\text { familiar with all } \\
\text { information shared, } \\
\text { but C4's comment } \\
\text { helped to connect } \\
\text { them }\end{array}$ & $\begin{array}{l}\text { Meaning- } \\
\text { making is } \\
\text { complete } \\
\text { (convergence } \\
\text { culture) }\end{array}$ & \\
\hline$[\ldots]$ & & & & \\
\hline
\end{tabular}

This is the Accepted Manuscript of an article published by Taylor \& Francis in International Journal of Mathematical Education in Science and Technology on 26 September 2020, available at https://www.tandfonline.com/doi/full/10.1080/0020739X.2020.1807069 


\begin{tabular}{|c|c|c|c|c|}
\hline $\begin{array}{l}\text { 6-C5: but i } \\
\text { thought we } \\
\text { used taylor } \\
\text { series to prove } \\
\text { that } \sin ^{\prime}=\cos \\
\text { tho }\end{array}$ & $\begin{array}{l}\text { Asks about the use } \\
\text { of Taylor series } \\
\text { instead of the limit } \\
\text { for the proof of the } \\
\text { derivative of sinx }\end{array}$ & $\begin{array}{l}\text { C5 indicates a lack of } \\
\text { information (need) } \\
\text { C4's answer does not } \\
\text { satisfy C5, C5 does } \\
\text { not (seem to) } \\
\text { recognize the role of } \\
\text { the limit in proving } \\
\text { sin'=cos }\end{array}$ & $\begin{array}{l}\text { C5 expresses } \\
\text { the need for } \\
\text { more } \\
\text { information } \\
\text { (convergence } \\
\text { culture) }\end{array}$ & \multirow{5}{*}{$\begin{array}{l}\text { Digging } \\
\text { deeper into the } \\
\text { usual steps of } \\
\text { proofs and } \\
\text { what makes } \\
\text { the reasoning } \\
\text { in the meme } \\
\text { circular }\end{array}$} \\
\hline $\begin{array}{l}\text { 7-C4: } \\
\text { [replying to } \\
\text { C5] you begin } \\
\text { with their } \\
\text { Taylor series } \\
\text { definitions? }\end{array}$ & $\begin{array}{l}\text { Asks about the first } \\
\text { step of the topic } \\
\text { (need for clarity) }\end{array}$ & $\begin{array}{l}\text { C4 is not evaluating } \\
\text { C5's comment, but } \\
\text { changes the focus of } \\
\text { the discussion to the } \\
\text { steps of the topic }\end{array}$ & $\begin{array}{l}\text { Informal } \\
\text { (didactic) } \\
\text { mentorship } \\
\text { (participatory } \\
\text { culture) }\end{array}$ & \\
\hline $\begin{array}{l}\text { 8-A: As long } \\
\text { as you } \\
\text { explicitly } \\
\text { show that } \mathrm{d} / \mathrm{dx} \\
\text { sinx = cosx } \\
\text { then you can } \\
\text { use l'hopitals } \\
\text { rule }\end{array}$ & $\begin{array}{l}\text { A intervenes to } \\
\text { clarify (to an } \\
\text { implicit need) } \\
\text { which are the } \\
\text { mutual } \\
\text { dependencies of the } \\
\text { steps }\end{array}$ & $\begin{array}{l}\text { A brings the } \\
\text { community back to } \\
\text { the original problem } \\
\text { Here the adverb } \\
\text { "explicitly" referred to } \\
\text { the proof of the } \\
\text { derivative is to be read } \\
\text { as independently of } \\
\text { the limit in the meme }\end{array}$ & $\begin{array}{l}\text { Informal } \\
\text { mentorship } \\
\text { giving a rule } \\
\text { (participatory } \\
\text { culture) }\end{array}$ & \\
\hline $\begin{array}{l}\text { 9-C5: ok nice ! } \\
\text { () }\end{array}$ & $\begin{array}{l}\text { Acknowledgement } \\
\text { and acceptance of } \\
\text { the explanations }\end{array}$ & $\begin{array}{l}\text { C5 reacts with } \\
\text { appreciation }\end{array}$ & $\begin{array}{l}\text { C5 completes } \\
\text { the meaning- } \\
\text { making } \\
\text { (convergence } \\
\text { culture) }\end{array}$ & \\
\hline $\begin{array}{l}\text { 10-C4: } \\
\text { [replying to A] } \\
\text { yeah, but in } \\
\text { rigor, } \\
\text { depending on } \\
\text { how you } \\
\text { begin, you } \\
\text { might need } \\
\text { first to prove } \\
\text { sin(x)/x. In the } \\
\text { usual } \\
\text { development } \\
\text { of the topics I } \\
\text { suppose it's the } \\
\text { case }\end{array}$ & $\begin{array}{l}\text { Replies to A } \\
\text { referring to the } \\
\text { established steps of } \\
\text { proofs: first the } \\
\text { limit and then the } \\
\text { derivative (as is } \\
\text { implied by the } \\
\text { meme) }\end{array}$ & $\begin{array}{l}\text { C4 focuses again on } \\
\text { the usual steps of } \\
\text { proofs with the limit } \\
\text { as the first step of the } \\
\text { usual development. C4 } \\
\text { connects this } \\
\text { interpretation to the } \\
\text { meme ("I suppose it's } \\
\text { the case"), meaning } \\
\text { this is the case where } \\
\text { the "mega wrong" } \\
\text { circularity occurs } \\
\text { (clarifies the usual } \\
\text { context of learning the } \\
\text { maths of the meme, } \\
\text { reacts to an implicit } \\
\text { need to clarify) }\end{array}$ & $\begin{array}{l}\text { C4 (coming } \\
\text { back to the } \\
\text { meme) } \\
\text { acknowledges } \\
\text { the fact that the } \\
\text { meme is } \\
\text { constructed } \\
\text { according to } \\
\text { what is } \\
\text { mathematically } \\
\text { consistent in the } \\
\text { usual way of } \\
\text { proving } \\
\text { (convergence } \\
\text { culture) }\end{array}$ & \\
\hline$[\ldots]$ & & & & \\
\hline
\end{tabular}

This is the Accepted Manuscript of an article published by Taylor \& Francis in International Journal of Mathematical Education in Science and Technology on 26 September 2020, available at https://www.tandfonline.com/doi/full/10.1080/0020739X.2020.1807069 


\begin{tabular}{|c|c|c|c|c|}
\hline $\begin{array}{l}\text { 11-A: } \\
\text { [replying to } \\
\text { C4] that's what } \\
\text { makes it } \\
\text { circular } \\
\text { reasoning } \\
\text { because you'll } \\
\text { use sinx/x to } \\
\text { show sin'x = } \\
\text { cosx and then } \\
\text { go use that to } \\
\text { prove sinx/x } \\
\text { notice how } \\
\text { that reasoning } \\
\text { goes in circles }\end{array}$ & $\begin{array}{l}\text { A explains in } \\
\text { details the logical } \\
\text { steps of the circular } \\
\text { reasoning occurring } \\
\text { if the steps of } \\
\text { proofs starts with } \\
\text { the limit } \\
\text { (reacts to need for } \\
\text { reasoning) }\end{array}$ & $\begin{array}{l}\text { A comes back to the } \\
\text { original meme and } \\
\text { acknowledges C4's } \\
\text { explanation of the } \\
\text { fallacy ("that's what } \\
\text { makes it circular } \\
\text { reasoning") and gives } \\
\text { a detailed explanation } \\
\text { ending with a } \\
\text { didactical observation } \\
\text { "notice how that } \\
\text { reasoning goes in } \\
\text { circles" }\end{array}$ & $\begin{array}{l}\text { A is self- } \\
\text { positioning in } \\
\text { the community } \\
\text { as an expert, } \\
\text { owning the } \\
\text { meme acting } \\
\text { toward a need to } \\
\text { decode } \\
\text { (participatory } \\
\text { culture) }\end{array}$ & \\
\hline $\begin{array}{l}\text { 12-C4: Yeah, I } \\
\text { said that in my } \\
\text { very first } \\
\text { comment, lol } \\
\text { [laugh out } \\
\text { loud] }\end{array}$ & Acknowledgement & $\begin{array}{l}\text { C4 points out that the } \\
\text { same clarification had } \\
\text { been already provided } \\
\text { and endorses A's }\end{array}$ & $\begin{array}{l}\text { C4 is self- } \\
\text { positioning at } \\
\text { the same level } \\
\text { of expertise } \\
\text { (participatory } \\
\text { culture) }\end{array}$ & \\
\hline \multicolumn{4}{|l|}{$[\ldots]$} & \multirow{4}{*}{$\begin{array}{l}\text { Proof of the } \\
\text { limit using the } \\
\text { sandwich } \\
\text { theorem }\end{array}$} \\
\hline $\begin{array}{l}\text { 13-C6: How is } \\
\text { it proved?? }\end{array}$ & $\begin{array}{l}\text { Clarification } \\
\text { request about the } \\
\text { proof of the limit } \\
\sin x / x\end{array}$ & $\begin{array}{l}\text { Based on the previous } \\
\text { comments and on the } \\
\text { meme, C6 expresses } \\
\text { the need for a proof of } \\
\text { the limit in the meme. } \\
\text { It may be part of the } \\
\text { sentence: if it is "mega } \\
\text { wrong" to prove it } \\
\text { with differentiation, } \\
\text { then how is it proved? }\end{array}$ & $\begin{array}{l}\text { C6 addresses } \\
\text { the community } \\
\text { as a knowledge } \\
\text { holder } \\
\text { (convergence } \\
\text { culture) }\end{array}$ & \\
\hline $\begin{array}{l}\text { 14-A: } \\
\text { [replying to } \\
\text { C6] Geometric } \\
\text { argument is the } \\
\text { easiest way }\end{array}$ & $\begin{array}{l}\text { A replies hinting to } \\
\text { the geometrical } \\
\text { proof of the limit }\end{array}$ & $\begin{array}{l}\text { A reacts to the need } \\
\text { for proof, stressing: } \\
\text { there are other not } \\
\text { mentioned proving } \\
\text { techniques and A is } \\
\text { able to select the } \\
\text { easiest one }\end{array}$ & $\begin{array}{l}\text { A is self- } \\
\text { positioning in } \\
\text { the community } \\
\text { as an expert, } \\
\text { offering } \\
\text { informal } \\
\text { mentoring } \\
\text { (participatory } \\
\text { culture) }\end{array}$ & \\
\hline $\begin{array}{l}\text { 15-C4: You } \\
\text { can } \\
\text { geometrically } \\
\text { prove } \sin (\mathrm{x}) \\
<=\mathrm{x}<=\tan (\mathrm{x}), \\
\text { divide by }\end{array}$ & $\begin{array}{l}\text { Description of the } \\
\text { steps of the } \\
\text { geometric proof } \\
\text { using the sandwich } \\
\text { (squeeze) theorem } \\
\text { to prove the limit }\end{array}$ & $\begin{array}{l}\text { The explanation is } \\
\text { consistent although } \\
\text { many elements are left } \\
\text { to the reader to fill in: } \\
\text { how to "geometrically } \\
\text { prove" the first }\end{array}$ & $\begin{array}{l}\text { Informal } \\
\text { mentorship is } \\
\text { worked out } \\
\text { (participatory } \\
\text { culture) }\end{array}$ & \\
\hline
\end{tabular}

This is the Accepted Manuscript of an article published by Taylor \& Francis in International Journal of Mathematical Education in Science and Technology on 26 September 2020, available at https://www.tandfonline.com/doi/full/10.1080/0020739X.2020.1807069 


\begin{tabular}{|c|c|c|c|c|}
\hline $\begin{array}{l}\sin (\mathrm{x}) \text { and use } \\
\text { the reciprocal } \\
\text { inequalities: } \\
\cos (\mathrm{x})<= \\
\sin (\mathrm{x}) / \mathrm{x}<=1 \\
\text { and then the } \\
\text { sandwich } \\
\text { theorem (plus } \\
\text { geometrical } \\
\text { demonstration } \\
\text { that } \cos (\mathrm{x})-> \\
\text { 1) }\end{array}$ & $\begin{array}{l}\text { (reacts to the need } \\
\text { to prove by offering } \\
\text { one) }\end{array}$ & $\begin{array}{l}\text { inequality and how the } \\
\text { sandwich theorem } \\
\text { actually works }\end{array}$ & & \\
\hline \multicolumn{5}{|l|}{$[\ldots]$} \\
\hline $\begin{array}{l}\text { 16-C7: So the } \\
\text { reason why } \\
\text { this doesn't } \\
\text { work is } d x / d y \\
\sin x=\cos x \text { is } \\
\text { proven by lim } \\
x->0 \sin x / x \\
=1 ?\end{array}$ & $\begin{array}{l}\text { Questions about the } \\
\text { wrap up of the } \\
\text { reasoning (reacts to } \\
\text { a need for } \\
\text { certainty) }\end{array}$ & $\begin{array}{l}\text { C7 summarizes the } \\
\text { reasoning towards the } \\
\text { others to confirm, } \\
\text { showing that C7 } \\
\text { followed the } \\
\text { discussion and } \\
\text { correctly grasped } \\
\text { "why this doesn't } \\
\text { work" }\end{array}$ & $\begin{array}{l}\text { C7 addresses } \\
\text { the community } \\
\text { as a knowledge } \\
\text { holder } \\
\text { (convergence } \\
\text { culture) }\end{array}$ & \multirow{2}{*}{$\begin{array}{l}\text { Final } \\
\text { consideration } \\
\text { about the } \\
\text { correctness of } \\
\text { the } \\
\text { mathematical } \\
\text { idea } \\
\text { represented by } \\
\text { the meme }\end{array}$} \\
\hline $\begin{array}{l}\text { 17-C4: [Day 1, } \\
\text { 17:11] } \\
\text { Generally }\end{array}$ & $\begin{array}{l}\text { Acknowledgement } \\
\text { according to the } \\
\text { usual way of } \\
\text { proving }\end{array}$ & $\begin{array}{l}\text { C4 does not notice } \mathrm{C} 7 \\
\text { final typo on the } \\
\text { derivative }(\mathrm{dx} / \mathrm{dy} \\
\text { instead of dy/dx) } \\
\text { possibly because the } \\
\text { focus is on the wrap } \\
\text { up of the reasoning }\end{array}$ & $\begin{array}{l}\text { Final informal } \\
\text { mentorship } \\
\text { (participatory } \\
\text { culture) }\end{array}$ & \\
\hline
\end{tabular}

The convergence culture is driven by different epistemic needs (Kidron et al., 2011) towards the understanding of the mathematics encoded in the meme: need for reasons (\#1, \#3), need for more information (\#6), need for clarity (\#7), need for argumentation premises (\#10), need for proof (\#13), need for certainty (\#16), where the latter seems to be the main one that underlies all the others. Kidron et al. (2011) focus on the epistemic orientation of needs, Drodge and Reid (2000) point to their emotional orientation in a mathematical activity, both indicate the relevance of the social when (epistemic) needs appear in a mathematical activity as in the participatory culture shown in the thread of comments.

The participatory culture is driven by the informal mentorship activated by the epistemic needs, even if sometimes implicitly: reacting to a need for explanation (\#2,\#4), clarity (\#8, \#10, This is the Accepted Manuscript of an article published by Taylor \& Francis in International Journal of Mathematical Education in Science and Technology on 26 September 2020, available at https://www.tandfonline.com/doi/full/10.1080/0020739X.2020.1807069 
\#16), and reasoning (\#11). Doing this, the commenters also show, keep, and address expert levels of mathematics according to the meme, offering as much information as needed, but no more, unless someone expresses an epistemic need (\#2). Sometimes commenters explain without someone asking for an explanation, in this case they play the role of mentors towards an implicit need for explanation in the group (\#8,\#11), similarly they clarify the argumentation spontaneously and refer to the original meme (\#10). We are aware that some of the users might be people with good math skills or even mathematics teachers, willingly offering their knowledge. What is new here is that less-skilled individuals do not hold back from interacting with more competent people, spontaneously showing epistemic needs and taking advantage of the informal opportunity to learn something.

Throughout the exchanges, the mathematical idea encoded in the meme is reconstructed producing and using information and knowledge by commenters, naturally enacting the different roles of teacher (A C2 C4) and learner (C1 C3 C5 C6 C7). A meaning-making process emerges, activated by the meme and kept by the epistemic culture, revealing an argumentation progression with different mathematical themes. The process is summarized in C7's final comment: applying L'Hôpital's rule to solve the limit means taking the derivative of sinx, AND the proof of the derivative of $\sin x$ is based on the knowledge of the same limit (in the high school developing of the topic), HENCE the reasoning is circular. THEREFORE, applying L'Hôpital's rule to solve the limit is mega wrong. It is interesting to note that C7 was not among the commenters who asked the initial questions, nonetheless the final remark shows us that $\mathrm{C7}$ read the preceding comments, and elaborated the information shared to produce some mathematical knowledge. In the progressing of the reasoning, some side knowledge is also produced, stemming from the acquired correctness of the meme in a mathematically consistent way: IF applying L'Hôpital's rule is mega wrong, THEN what is the correct solving procedure?

This is the Accepted Manuscript of an article published by Taylor \& Francis in International Journal of Mathematical Education in Science and Technology on 26 September 2020, available at https://www.tandfonline.com/doi/full/10.1080/0020739X.2020.1807069 
Drawing together, the meaning-making process takes the form of an argumentation nurtured by an epistemic culture. This epistemic culture is established and re-established by the interplay between the convergence culture driven by epistemic needs and the participatory culture where the community members react towards explicit or implicit epistemic needs by explaining, clarifying, and reasoning. In this epistemic culture, the negotiation of knowledge is expert-like, recognizing the other as experts in the community, mutually offering and asking for mentorship.

\section{Case 2: the wrong meme}

- Meme base name: Spiderman pointing at Spiderman

- Meme base use: describe situations in which similar elements meet

- Source: Facebook Total comments: 131

- Topic: Functions

- Subtopic: Direct and inverse trig functions

- Critical point: misinterpreted equivalence between $f^{-1}(x)$ and $\frac{1}{f(x)}$

- Publication year: 2018
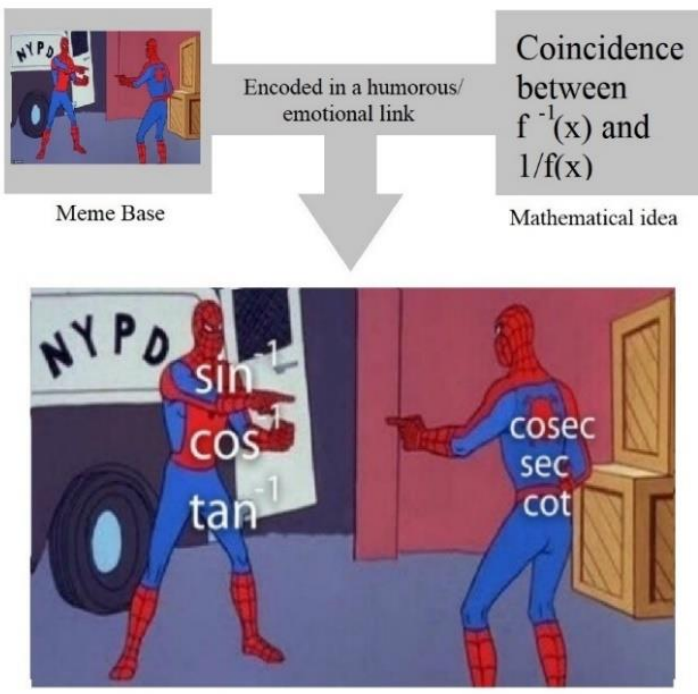

Figure 18. Case 2: the memetic analysis

Contextual description: The image of this meme in Figure 18 is commonly used to describe situations in which similar elements meet: in this case, the intent of the author is to 
represent the equivalence between the triplets of functions $\sin ^{-1} \cos ^{-1} \tan ^{-1}$ and cosec sec cot.

This equivalence is, of course, incorrect: the excerpt (Table 3) shows how swift and enduring

the online community is in singling out and discussing the mistake.

Table 3. Case 2 - the cultural analysis

\begin{tabular}{|c|c|c|c|c|}
\hline Comments & $\begin{array}{l}\text { Explicit } \\
\text { information }\end{array}$ & Implicit information & $\begin{array}{l}\text { Environmental } \\
\text { culture }\end{array}$ & $\begin{array}{l}\text { Emerging } \\
\text { mathematical } \\
\text { themes }\end{array}$ \\
\hline $\begin{array}{l}1-\mathrm{C} 1 \text { [Day } 1,9: 22] \text { : This } \\
\text { is mathematically wrong }\end{array}$ & $\begin{array}{l}\mathrm{C} 1 \text { declares the } \\
\text { meme as } \\
\text { incorrect }\end{array}$ & $\begin{array}{l}\text { By using the adverb } \\
\text { mathematically } \mathrm{C} 1 \\
\text { makes clear that the } \\
\text { problem is a } \\
\text { mathematical one } \\
\text { and not a memetic } \\
\text { one }\end{array}$ & $\begin{array}{l}\mathrm{C} 1 \text { addresses } \mathrm{A} \\
\text { as a teacher, } \\
\text { pointing to the } \\
\text { mistake } \\
\text { (participatory } \\
\text { culture) }\end{array}$ & \multirow{5}{*}{$\begin{array}{l}\text { Difference } \\
\text { between } \frac{1}{f(x)} \\
\text { and } f^{-1}(x)\end{array}$} \\
\hline \multicolumn{3}{|l|}{$[\ldots]$} & & \\
\hline $\begin{array}{l}\text { 2-A: Some people are } \\
\text { trying to be buzzkills by } \\
\text { saying } \sin ^{\wedge}-1 \text { is angle } \\
\text { and } 1 / \sin \text { is the actual } \\
\text { ratio(cosec). However, } \\
\text { those smart alecks don't } \\
\text { realise the first mistake } \\
\text { of the meme is that I } \\
\text { didn't even mention the } \\
\text { angle unit or anything } \\
\text { lol. Try scrutinizing a } \\
\text { little harder. }\end{array}$ & $\begin{array}{l}\text { A defends the } \\
\text { position, sharing } \\
\text { information } \\
\text { about what is } \\
\text { considered as the } \\
\text { first mistake in } \\
\text { the meme which } \\
\text { was not captured } \\
\text { by the } \\
\text { community }\end{array}$ & $\begin{array}{l}\text { A attacks C1 making } \\
\text { fun of C1's } \\
\text { mathematical } \\
\text { smartness (smart } \\
\text { aleck = geek) } \\
\text { The use of the slang } \\
\text { word buzzkill } \\
\text { (someone who ruins } \\
\text { something } \\
\text { enjoyable) tells us } \\
\text { that A perceives } \\
\text { memes as jokes } \\
\text { rather than as } \\
\text { mathematical objects }\end{array}$ & $\begin{array}{l}\text { A refuses to be } \\
\text { treated as a } \\
\text { student and } \\
\text { enters a } \\
\text { competition } \\
\text { about } \\
\text { mathematical } \\
\text { knowledge } \\
\text { (participatory } \\
\text { culture) }\end{array}$ & \\
\hline $\begin{array}{l}\text { 3-C1: nice comeback } \\
\text { after the mistake (:) :) }\end{array}$ & $\begin{array}{l}\text { Ironically } \\
\text { confirms the } \\
\text { mistake }\end{array}$ & $\begin{array}{l}\mathrm{C} 1 \text { gives a } \\
\text { patronizing } \\
\text { comment that } \\
\text { positions A at a } \\
\text { lower level of } \\
\text { expertise } \\
\text { The emoji says } \\
\text { "don't take it too } \\
\text { seriously" }\end{array}$ & $\begin{array}{l}\mathrm{C} 1 \text { is self- } \\
\text { positioning as an } \\
\text { expert } \\
\text { (participatory } \\
\text { culture) }\end{array}$ & \\
\hline $\begin{array}{l}\text { 4-C2: Arcsin can be } 0 \\
\text { while csec can not. same } \\
\text { for the arccos and sec }\end{array}$ & $\begin{array}{l}\text { Observes that the } \\
\text { value } 0 \text { is in the } \\
\text { range of the } \\
\text { function arcsin } \\
\text { (or arcos) while } \\
\text { it is not in the } \\
\text { range of the } \\
\text { function csec (or } \\
\text { sec) (reacts to an } \\
\text { implicit need for } \\
\text { a disprove) }\end{array}$ & $\begin{array}{l}\mathrm{C} 2 \text { offers an } \\
\text { explanation of why } \\
\text { the meme is } \\
\text { mathematically } \\
\text { wrong: if the } \\
\text { codomains of the } \\
\text { two functions are } \\
\text { different therefore } \\
\text { the functions cannot } \\
\text { be in the relation } \\
\text { implied by the meme }\end{array}$ & $\begin{array}{l}\text { Informal } \\
\text { mentorship } \\
\text { (participatory } \\
\text { culture) }\end{array}$ & \\
\hline
\end{tabular}

This is the Accepted Manuscript of an article published by Taylor \& Francis in International Journal of Mathematical Education in Science and Technology on 26 September 2020, available at https://www.tandfonline.com/doi/full/10.1080/0020739X.2020.1807069 


\begin{tabular}{|c|c|c|c|c|}
\hline & & $\begin{array}{l}\text { (one example is } \\
\text { enough) }\end{array}$ & & \\
\hline $\begin{array}{l}\text { 5-C3: The } \wedge_{-}-1 \text { doesnt } \\
\text { necessarily means that } \\
\text { they are a ratio it a sign } \\
\text { that its inverse of that } \\
\text { trig fn }\end{array}$ & $\begin{array}{l}\text { Explains the } \\
\text { misunderstanding } \\
\text { connected to the } \\
\text { different } \\
\text { meanings of the } \\
\text { notation }{ }^{\wedge}-1\end{array}$ & $\begin{array}{l}\text { The use of the term } \\
\text { necessarily gives the } \\
\text { idea that } C 3 \\
\text { acknowledges the } \\
\text { common meaning of } \\
\text { the }{ }^{\wedge}-1 \text { sign for } \\
\text { ratios (building on } \\
\text { A's comment), but }^{\prime} \text { wants to make clear } \\
\text { that there is another } \\
\text { meaning }\end{array}$ & $\begin{array}{l}\text { Informal } \\
\text { mentorship } \\
\text { expressly } \\
\text { directed towards } \\
\text { A (participatory } \\
\text { culture) }\end{array}$ & \\
\hline \multicolumn{5}{|l|}{$[\ldots]$} \\
\hline $\begin{array}{l}\text { 6-C4: [replying to A] } \\
\text { Whatever u say it's } \\
\text { wrong even if there's no } \\
\text { angle. An inverse trig } \\
\text { function is not the same } \\
\text { as raising it to -1 making } \\
\text { it a reciprocal of itself. } \\
\text { This meme is wrong, } \\
\text { accept it!!! (2) } \\
\text { [in a separate comment] } \\
\text { Also you can't raise a } \\
\text { function to -1 and say } \\
\text { that it's a reciprocal. } \\
\text { You only do that to } \\
\text { variables especially the } \\
\text { independent ones like } \\
\text { (x). Hahahha just } \\
\text { commenting in behalf of } \\
\text { the dumb alecks (2) [...] }\end{array}$ & $\begin{array}{l}\text { C4 confirms the } \\
\text { mistake and } \\
\text { explains that the } \\
\text { notation } \wedge^{\wedge}-1 \\
\text { means reciprocal } \\
\text { only when } \\
\text { applied to } \\
\text { variables }\end{array}$ & $\begin{array}{l}\text { C4 replies to A's } \\
\text { defense confirming } \\
\text { the mistake even if } \\
\text { there's no angle } \\
\text { C4'sconclusion } \\
\text { about these } \\
\text { comments being for } \\
\text { dumb alecks (nice } \\
\text { but not very clever } \\
\text { guys) implies that } \\
\text { C4's observations } \\
\text { are well known } \\
\text { mathematical facts } \\
\text { that A does not } \\
\text { know. }\end{array}$ & $\begin{array}{l}\text { Mathematical } \\
\text { memes as } \\
\text { membership } \\
\text { identifiers, thus } \\
\text { they must follow } \\
\text { the norm to be } \\
\text { mathemati-cally } \\
\text { correct } \\
\text { (participatory } \\
\text { culture) }\end{array}$ & \\
\hline $\begin{array}{l}\text { 7-C5: [replying to A] } \\
\text { Imagine trying to justify } \\
\text { the conflation of } \\
\text { different mathematical } \\
\text { identities by saying you } \\
\text { weren't using units. Nice } \\
\text { try, but have you ever } \\
\text { heard of a functions } \\
\text { domain? Trig functions } \\
\text { have domains from -1 to } \\
1 \text { (except tangent) unless } \\
\text { you're using complex } \\
\text { analysis to define them } \\
\text { in some other way, } \\
\text { which most people } \\
\text { aren't. Just accept that } \\
\text { you're wrong }\end{array}$ & $\begin{array}{l}\text { Reply to A's } \\
\text { defense about the } \\
\text { missing angle } \\
\text { units, confirming } \\
\text { the mistake }\end{array}$ & $\begin{array}{l}\text { C5 supports A's } \\
\text { comment bringing in } \\
\text { a not well related } \\
\text { argument about } \\
\text { functions range } \\
\text { (erroneously referred } \\
\text { to as domain) }\end{array}$ & $\begin{array}{l}\text { C5 is self- } \\
\text { positioning as an } \\
\text { expert, allowed } \\
\text { to mentor } \\
\text { (participatory } \\
\text { culture) }\end{array}$ & $\begin{array}{l}\text { Domain and } \\
\text { codomain of a } \\
\text { function }\end{array}$ \\
\hline
\end{tabular}

This is the Accepted Manuscript of an article published by Taylor \& Francis in International Journal of Mathematical Education in Science and Technology on 26 September 2020, available at https://www.tandfonline.com/doi/full/10.1080/0020739X.2020.1807069 


\begin{tabular}{|c|c|c|c|c|}
\hline $\begin{array}{l}8 \text {-A: [Day } 3,17: 10] \text { I } \\
\text { did admit I was wrong } \\
\text { lol. } \\
\text { If you think I don't } \\
\text { know anything about } \\
\text { trigonometric ratios and } \\
\text { angle, then hear this: } \\
\text { sin=1/cosec } \\
\text { cos=1/sec } \\
\text { tan=1/cot } \\
\text { Whenever there's an } \\
\text { inverse (^-1), it becomes } \\
\text { the value of an angle. } \\
\text { Also, (sin or cos or } \\
\text { tan)^-1 =arc(sin or cos } \\
\text { or tan), which I learnt } \\
\text { after making the } \\
\text { mistake. } \\
\text { Moreover, another } \\
\text { admin made this meme. } \\
\text { The idea was just mine. } \\
\text { And idk [I don't know] } \\
\text { what you are saying } \\
\text { about domain. } \\
\text { You probably wanted to } \\
\text { say codomain. } \\
\text { I hope I don't have to } \\
\text { justify myself anymore. } \\
\text { I am just in school } \\
\text { NIBBA. [a slang word } \\
\text { for "guys"] }\end{array}$ & $\begin{array}{l}\text { A acknowledges } \\
\text { the mistake, } \\
\text { shows what has } \\
\text { been learned and } \\
\text { identifies C5's } \\
\text { mistake about the } \\
\text { domain }\end{array}$ & $\begin{array}{l}\text { Given the time span } \\
\text { between the initial } \\
\text { comment and this, A } \\
\text { likely uses external } \\
\text { resource to } \\
\text { straighten the issue. } \\
\text { A comes back to } \\
\text { recognize the } \\
\text { mistake and show } \\
\text { off the newly } \\
\text { acquired knowledge, } \\
\text { learnt after making } \\
\text { the mistake, scoring } \\
\text { a point towards C5's } \\
\text { domain/ codomain } \\
\text { jumble. } \\
\text { The new knowledge } \\
\text { is exposed with } \\
\text { emphasis, both } \\
\text { verbal (hear this) } \\
\text { and structural, in the } \\
\text { layout of the writing } \\
\text { (as opposed to the } \\
\text { usual in line } \\
\text { comments) to make } \\
\text { concepts stand out. } \\
\text { Dilemma: A wants } \\
\text { to be acknowledged } \\
\text { vs. uses the school } \\
\text { background as an } \\
\text { excuse for the } \\
\text { mistake }\end{array}$ & $\begin{array}{l}\text { A accepts the } \\
\text { norm and } \\
\text { achieves the } \\
\text { meaning-making } \\
\text { (convergence } \\
\text { culture) } \\
\text { A generalizes the } \\
\text { norm to the } \\
\text { behaviour in the } \\
\text { community } \\
\text { addressing C5's } \\
\text { mistake } \\
\text { (participatory } \\
\text { culture) }\end{array}$ & $\begin{array}{l}\text { Final } \\
\text { consideration } \\
\text { about the } \\
\text { incorrectness } \\
\text { of the } \\
\text { mathematical } \\
\text { idea } \\
\text { represented by } \\
\text { the meme }\end{array}$ \\
\hline $\begin{array}{l}\text { 9-C5 [Day 4, 04:22 } \\
\text { Understandable }\end{array}$ & $\begin{array}{l}\text { C5's closing } \\
\text { comment replies } \\
\text { only to A's } \\
\text { excuse for the } \\
\text { mistake and } \\
\text { accepts it }\end{array}$ & $\begin{array}{l}\text { When A shows some } \\
\text { willingness to learn } \\
\text { and reveals as a high } \\
\text { school student, C5 } \\
\text { recognizes A the } \\
\text { right to make } \\
\text { mistakes }\end{array}$ & $\begin{array}{l}\text { Final informal } \\
\text { mentorship } \\
\text { (participatory } \\
\text { culture) }\end{array}$ & \\
\hline
\end{tabular}

C1 shows the need to check the correctness of the meme mathematically. This initiates a negotiation on how a meme and the encoded mathematics should be perceived, either as a mathematical object or as a joke (\#2,\#3). A's defence is initially not accepted (\#3, \#6, \#7) as A's comment does not show any epistemic need to reason or ask for reasons necessary when something is incorrect. In the following interactions the epistemic culture is re-established by the participatory culture which is usually implemented in the community. The comments 
express actions towards needs aimed at disproving the mathematical idea encoded in the meme (\#4), giving reasons (\#4, \#5, \#6, \#7), explaining (\#5, \#6), and mentoring others (\#6, \#7). The community is strongly committed to the fact that the mathematics encoded in the meme must be mathematically correct (\#6, 7\#). The commenters' participation can be taken as expressing what experts do with incorrect mathematical ideas: they take them in and disprove them, showing a need for proof and its underlying need for certainty.

The incorrectness of the meme is finally recognized by A (\#8). By finding mistakes in the experts' comments, too, A appears not fully acquainted with the epistemic culture established in the community, which tolerates mistakes in the epistemic interaction but not in the meme. By stressing that the meme was another admin's creation, A refuses to take responsibility for the mistake (apologizing), showing a need to explain the background situation rather than an epistemic need. A uses the declared status of high school students as an excuse for the incorrectness of the meme. However, as soon as A shows some willingness to learn, the mistake is accepted (\#9).

The convergent meaning-making process about the incorrectness of the mathematical idea represented by the meme comes about only in the end, hindered by A's initial reluctance (\#2). This can be interpreted as an evidence of the perceived value of these digital objects as identifiers of the belonging to the community. Three commenters ( $\mathrm{C} 2 \mathrm{C} 3 \mathrm{C} 4)$ provide diversified and mathematically consistent information, from counterexamples to notation conventions, aimed at sustaining the first negative comment $(\mathrm{C} 1)$. Finally, some mathematical knowledge is constructed: A acknowledges the mistake made but at the same time tries to reaffirm the position in the group by making in turn note $\mathrm{C} 5$ 's domain/codomain error.

Drawing all together, we have reconstructed the practices of convergence and participation in this community. Community members share the norm that the mathematics in the meme must be correct. Epistemic needs related to the memes drive the meaning-making 
(convergence), from there members act fulfilling the needs based on the norm of keeping a certain expert level but being also open to include those who express epistemic needs. We call this the meme epistemic culture, fostering a process of argumentation, driven by epistemic needs, resulting in proofs and clarifications around the mathematical idea in the meme.

These two polar types epitomize a practice that our participant observation revealed as characteristic for the interaction with mathematical memes in dedicated online communities. Indeed, our comment pool investigation showed that, apart from emojis and friends tagging, comments to mathematical memes are always at the mathematical level, aimed at proving or disproving the mathematical idea encoded in the meme, and never at the memetic level (e.g. asking explanations about the meaning of a particular image). We take this as evidence of the fact that users are familiar with the rules of the memesphere and therefore do not need support in this field. However, this indicates also that these communities perceive mathematical memes as mathematical objects rather than as entertaining objects, as suggested by name choices as Mathematical Mathematics Memes. Another relevant point is that, even if the understanding of a mathematical meme requires the decoding of the encoded link, comments do not make this decoding process explicit. E.g., in case $2, \mathrm{C} 1$ does not write "the equalities $\sin ^{-1}=\operatorname{cosec}, \cos ^{-}$ ${ }^{1}=\sec$ and $\tan ^{-1}=\cot$ are mathematically wrong", but simply "the meme is mathematically wrong" (\#1), assuming that everybody gets the equalities encoded in the meme. Comments are all directed towards giving arguments to prove or disprove the mathematical idea expressed by the meme, explaining why the functions are different or explaining why using L'Hôpital's rule to solve the limit is incorrect.

To sum up, interacting with a mathematical meme implies a two-step process: the first step is the decoding of the mathematical idea, and the second step is the argumentation needed to determine whether this mathematical idea is correct or incorrect. The first step requires memetic and mathematical knowledges: this step is not externalized in the comments; thus, we 
assume that users achieve it on their own. The second step requires mathematical knowledge only and is what the community actively engages in: a collective meaning-making process of the correctness of the mathematical idea, activated by an epistemic culture. This meme epistemic culture even enriches the epistemic process with further clarifications about the mathematical theme, for example offering more than just one proof although one would be enough or explaining concepts at the periphery of the meme.

\section{Results and theorizing towards a conceptualization of the phenomenon}

Our research questions aimed at characterizing the Internet phenomenon of mathematical memes as a new form of representation of mathematical ideas and at exploring how they activate interactions among members of online communities. We have investigated these issues applying a twofold theoretical background to a participant observation of the field and an instrumental case study. Results are summarized in Table 4.

Table 4. A summary of the findings

\begin{tabular}{|c|c|c|}
\hline \multirow{2}{*}{ 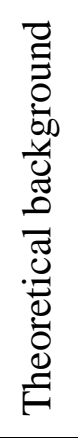 } & 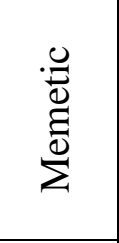 & $\begin{array}{l}\text { The memetic constituent elements of mathematical memes are: } \\
\text { humour and emotions, spreadability and diffusion, and image macros } \\
\text { structural and compositional rules. In mathematical memes images are used to } \\
\text { represent effects (tangible or emotional, always mathematically rigorous) or } \\
\text { elements of the mathematical idea hinted by the text }\end{array}$ \\
\hline & 菛 & $\begin{array}{l}\text { The cultural features of the Web } 2.0 \text { that inspire the production and use of } \\
\text { mathematical memes are participatory culture and convergence culture. These } \\
\text { features shape the perceptions of mathematical memes as membership } \\
\text { identifiers and as learning opportunities inside the communities }\end{array}$ \\
\hline \multirow{2}{*}{ 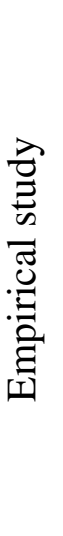 } & 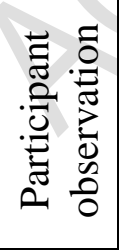 & $\begin{array}{l}\text { Threads of comments with explicated mathematics are a characterising } \\
\text { practice of the interaction with mathematical memes as representations of } \\
\text { mathematical ideas. This practice is highly respected inside the community, } \\
\text { where mathematical memes and the accompanying comments are recognised } \\
\text { for their educational value. }\end{array}$ \\
\hline & 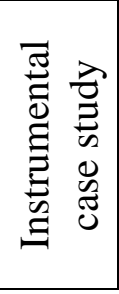 & $\begin{array}{l}\text { The interaction with mathematical memes as representations of mathematical } \\
\text { ideas revealed in the threads of comments focuses on discussing the } \\
\text { correctness of the mathematical idea encoded in the meme. In these } \\
\text { interactions, epistemic needs are activated. They drive the discussion, handled } \\
\text { with rigor, resulting in a process of transfer of mathematical knowledge, where } \\
\text { engagement is highly valued }\end{array}$ \\
\hline
\end{tabular}

This is the Accepted Manuscript of an article published by Taylor \& Francis in International Journal of Mathematical Education in Science and Technology on 26 September 2020, available at https://www.tandfonline.com/doi/full/10.1080/0020739X.2020.1807069 
The memetic and cultural perspectives provide grounds to characterize mathematical memes as humorous and spreadable artefacts where images and texts are combined to represent mathematical ideas. They are cultural objects, created respecting both the laws of the memesphere and those of mathematics, and shared within dedicated communities to acquire a status. Participant observation and a case study illustrate mathematical memes' educational potential, provided by the epistemic culture activated by the meme itself and leading to a collective meaning-making (cf. Kruglanski, 2010). The meme epistemic culture in the communities is (re-)established by an embedding participatory culture of acting epistemically, and by a convergence culture driven by epistemic needs. Members of the communities spontaneously tend to organize themselves according to a social order depending on mathematical skills, and interact following shared sociomathematical as well as social norms (Yackel \& Cobb, 1996). The key sociomathematical norm requires mathematical memes to be correct, a key social norm implies, among others, an assumption of expertise, which manifests itself in the fact that, unless epistemic needs are expressed, commenters never overexplain.

These results allow us to move further in conceptualizing the phenomenon. We have seen that comments focus mainly on the rigorous assessment of the correctness or incorrectness of the mathematical idea encoded in the meme. Our explanation is that mathematical memes represent mathematical ideas by their properties that can be logically proved or disproved. Therefore, we hypothesize through abduction (Peirce, 1931, CP 5.189; cf. Arzarello et al., 1998; Douven, 2011) that mathematical memes represent mathematical statements in the sense of propositional logic (Durand-Guerrier, 2008; Cook, 2009), that is declarative propositions whose truth-value can be determined as either true or false through logically valid arguments (i.e. arguments that originate from premises assumed as true and that develop in a truth-preserving way).

From this, we propose a conceptualization of the observed phenomenon: 
Mathematical memes represent mathematical statements. Elements that compose the statement can come from the textual part, from the image or from a combination of the two, in a new hybrid language which merges mathematical elements with memetic elements, rigorously abiding by the rules of both fields. The need to determine the truth-value of the statement evokes a negotiation shaped by an epistemic culture on the mathematics encoded.

To validate this hypothesis, we tested it on our meme pool. For each and all of the collected memes we were able to express the matching statement. Due to space constraints, we will only show here the correspondence between mathematical memes previously presented in this paper and the related statements, along with their truth-value (Table 5).

Table 5. Mathematical memes as statements

\begin{tabular}{|c|c|c|c|}
\hline Fig. & Meme & Statement & $\begin{array}{l}\text { Truth- } \\
\text { value }\end{array}$ \\
\hline $3 \mathrm{a}$ & Me and the boys & $y=x^{x}$ cannot be integrated in elementary terms & True \\
\hline $3 b$ & Me and the boys & $\begin{array}{l}y=\frac{\sin x}{x}, y=e^{-x^{2}}, y=\sqrt{\sin x}, y= \\
\sqrt{1+x^{3}} \text { cannot be integrated in elementary terms }\end{array}$ & True \\
\hline 4 & Me and the boys & $\begin{array}{l}\text { In the complex plane, the effect of multiplying by } \mathrm{i} \\
\text { is a } \frac{\pi}{2} \text { rotation }\end{array}$ & True \\
\hline 10 & Success kid & $(a+b)^{2}=a^{2}+2 a b+b^{2}$ & True \\
\hline 11 & $\begin{array}{l}\text { Spiderman } \\
\text { pointing at } \\
\text { Spiderman }\end{array}$ & $\frac{d}{d x}\left(e^{x}\right)=e^{x}$ & True \\
\hline 17 & Mega wron & $\begin{array}{l}\text { Evaluating } \lim _{x \rightarrow 0} \frac{\sin x}{x} \text { with L'Hôpital's rule is a } \\
\text { logical fallacy }\end{array}$ & $\begin{array}{l}\text { True } \\
\text { (assuming } \\
\text { certain } \\
\text { premises) }\end{array}$ \\
\hline 18 & $\begin{array}{l}\text { Spiderman } \\
\text { pointing at } \\
\text { Spiderman } \\
\end{array}$ & $\begin{array}{l}\sin ^{-1}(\alpha)=\operatorname{cosec} \alpha ; \cos ^{-1}(\alpha) \\
=\sec \alpha ; \tan ^{-1}(\alpha)=\cot \alpha\end{array}$ & False \\
\hline
\end{tabular}

This conceptualization fits with all the characteristics that emerged from our empirical analysis: it explains that

- mathematical memes are rigorously formulated from the memetic and mathematical standpoint because they are mathematical statements,

- they are taken as membership identifiers as they display mathematical expertise,

- the discussion focuses on their truth-value and, thus, mobilizes mathematical information and knowledge as prerequisites for (dis-)proving and understanding.

This is the Accepted Manuscript of an article published by Taylor \& Francis in International Journal of Mathematical Education in Science and Technology on 26 September 2020, available at https://www.tandfonline.com/doi/full/10.1080/0020739X.2020.1807069 
It also explains why memes are not explicitly decoded in the comments, as the community members are aware that paraphrasing a statement does not count in the process of argumentation.

Given that mathematical memes represent mathematical statements, we can differentiate what is and what is not a manifestation of the phenomenon, distinguishing these objects from other digital objects shared within these communities, as emotional memes and cartoons. In fact, the emotional meme seen in Figure 14a conveys the message math is puzzling, which is not a mathematical statement, because its truth-value is subjectively evaluated. While the cartoon in Figure 14b, offers a cartoonised version of the effect of the Fourier transform that cannot be translated into a provable or disprovable mathematical statement, as opposed to the Me and the boys multiplying by $i$ meme in Figure 4.

Going back to Gitelman's two-level model for media cited at the beginning (2006), we can say that a mathematical meme is firstly a technology that enables the communication of mathematical statement. Secondly, a mathematical meme is embedded in a set of social practices and cultural norms, implying that the mathematical statement must be true, and shaping an epistemic culture where the meme activates and guides epistemic processes about the mathematics addressed in the statement.

\section{Discussion, reflection, concluding remarks}

Ordinary mathematical representations can take the form of numerical, algebraic, graphical, verbal mathematical expressions, sometimes including logic operators (Goldin, 2014). They are formal, relieved from any possible emotion that mathematics can spark. Not so in the representation of mathematical memes, where mathematical statements are taken as rigorously as in mathematics but their decoding requires additional knowledge from the memesphere. Only a deep understanding of the encoded mathematics unfolds the power of the joke in the meme. Such a hybrid representation of a mathematical statement is no longer dry, it addresses 
emotions although being rigorous with respect to mathematics. This may provide widened access to mathematics for an enlarged range of learners.

Our conceptualization resulted in the insight that mathematical memes represent statements and activate an epistemic culture in the online community. This is an important finding pointing to their educational potential for constructing mathematical knowledge. It expands and updates our semiotic capital to represent mathematics. Following O'Halloran's idea that "a culture may be understood as a typical configuration of choices from a variety of semiotic resources" (2005, p. 6), this can open new research paths of investigating hybrid representational systems in mathematics. Another research path may address learning in everyday classrooms, investigating there how mathematical memes activate and drive mathematical discussions and how this fosters interest in mathematics.

Our findings can also be a first step to figure out how mathematical memes can be used for teaching in traditional educational settings. In fact, statements are the building blocks of mathematics and proving statements is the building block of any mathematical activity. Thus, mathematical memes could be used in argumentation-based learning scenarios, where their manifestation as objects closer to students' experience than to classical mathematical registers can leverage on learners' popular culture to engage students in the essential mathematical practice of justification.

Naturally, this work has some limitations. As a case study, although taken from and supported by a big meme pool, our findings do not offer information about the scope of the study, e.g. how other online communities treat these memes or if there are online communities creating mathematical memes that cannot be taken as statements. Further, we do not know the members of these communities and the time they invest in making the communities work as shown in the investigation. But our study has also a certain strength: our conceptualizing is ecologically valid, because it is rooted in the ethnographic approach which made us gain data 
of high ecological validity. As a lurker, the observer knew what was relevant for community members but also was controlling this by comprehensive data collections and analyses. Ecological validity was further substantiated by mapping the field with a systematic funnelling procedure to gain paradigmatic cases for our theorizing, which added ecologically significant data to be analysed on a micro level from inside the interaction in the communities.

This empirically founded conceptualizing could provide a well-established basis for further investigations of the memesphere and testing of our findings. Since we have gained a new kind of representation, semiosis related to discussing the meme' mathematical ideas could reveal deeper insight into the mechanisms of knowledge construction activated by the meme, and semiosis related to meme mutations could reveal scientific as well as educational knowledge of the encoding mechanisms, which may inform teaching.

Observing that Internet culture is in constant change, we conclude that we cannot predict if, a few years from now, mathematical memes will still have the same characteristics as those described in this study or will exist altogether. Nonetheless, even if memes, as we know them, will go out of fashion or morph into something different, the present work aspires to be a first step in the investigation of the evolving epistemic mechanisms of the new generation of convergent and participant learners, with a value that may go beyond memes and their possible transience.

Acknowledgements: We would like to thank Zsolt Lavicza and Nathalie Sinclair for their encouraging support at the beginning of this project. We are also grateful to Gabriel García Márquez for providing inspiration for the title of this work.

\section{Footnotes}

\section{1.https://www.oxfordlearnersdictionaries.com/definition/english/meme}

2.To protect the privacy of commenters, personal identifiers have been substituted with codes throughout the study.

3.https://www.statista.com/statistics/272014/global-social-networks-ranked-by-number-ofusers/

This is the Accepted Manuscript of an article published by Taylor \& Francis in International Journal of Mathematical Education in Science and Technology on 26 September 2020, available at https://www.tandfonline.com/doi/full/10.1080/0020739X.2020.1807069 
4.http://www.indire.it/lucabas/lkmw_file/licei2010/indicazioni_nuovo_impaginato/_Liceo\%2 Oscientifico.pdf

5.https://wearesocial.com/global-digital-report-2019

6.https://www.edisonresearch.com/wp-content/uploads/2019/03/Infinite-Dial-2019-PDF-1.pdf

\section{Conflict of interest statement}

All authors declare that they have no conflict of interest.

\section{References}

Anonymous 4chan Poster, Houston, R., Pantone, J., \& Vatter, V. (2018). A lower bound on the length of the shortest superpattern. OEIS. https://oeis.org/A180632/a180632.pdf

Arzarello, F., Andriano, V., Olivero, F., \& Robutti, O. (1998). Abduction and conjecturing in mathematics. Philosophica, 61(1), 77-94.

Balacheff, N. (1988). Une étude des processus de preuve en mathématique chez des élèves de collège [A study of proof processes in mathematics in college students]. [Doctoral dissertation, Institut National Polytechnique de Grenoble]. Université J. Fourier https://tel.archives-ouvertes.fr/tel-00326426

Benoit, G. (2018). Mathematics in popular culture: An analysis of mathematical Internet memes [Doctoral dissertation, Teachers College, Columbia University]. Columbia University Library. https://doi.org/10.7916/D8BG45GT

Beltrán-Pellicer, P. (2016). Utilizando memes con tus alumnos [Using memes with your students]. Números, 91, 129-134. http://www.sinewton.org/numeros/numeros/91/Experaula.pdf

Bini, G., \& Robutti, O. (2019a). Meanings in mathematics: Using Internet memes and augmented reality to promote mathematical discourse. In U. T. Jankvist, M. van den Heuvel-Panhuizen, \& M. Veldhuis (Eds.), Proceedings of the Eleventh Congress of the European Society for Research in Mathematics Education. Freudenthal Group \& Freudenthal Institute, Utrecht University and ERME. https://hal.archivesouvertes.fr/hal-02422152

Bini, G., \& Robutti, O. (2019b). Thinking inside the post: Investigating the didactic use of mathematical Internet memes. In A. Shvarts (Ed.), Proceedings of the PME and Yandex Russian conference "Technology and Psychology for Mathematics Education” (pp. 106-113). HSE Publishing House. http://www.igpme.org/wpcontent/uploads/2020/01/PMEYandex2019Final.pdf

Bini, G., \& Robutti, O. (2019c). Yo Math Is So Arty: Inspiring Creative Learning with Mathematical Internet Memes. In S. Goldstine, D. McKenna, \& K. Fenyvesi (Eds.), Proceedings of Bridges 2019: Mathematics, Art, Music, Architecture, Education, Culture (pp. 583-586). Tessellations Publishing. http://archive.bridgesmathart.org/2019/bridges2019-583.pdf

Börzsei, L. K. (2013). Makes a meme instead: A concise history of Internet memes. New Media Studies, 7, 152-183. https://works.bepress.com/linda_borzsei/2/

This is the Accepted Manuscript of an article published by Taylor \& Francis in International Journal of Mathematical Education in Science and Technology on 26 September 2020, available at https://www.tandfonline.com/doi/full/10.1080/0020739X.2020.1807069 
Bruns, A. (2008). Blogs, Wikipedia, second life, and beyond: from production to produsage. Peter Lang. https://www.peterlang.com/view/title/58788

Cannizzaro, S. (2016). Internet memes as Internet signs: A semiotic view of digital culture. Sign Systems Studies. 44(4), 562-586. https://doi.org/10.12697/SSS.2016.44.4.05

Cook, R. (2009). A dictionary of philosophical logic. Edinburgh University Press. https://www.jstor.org/stable/10.3366/j.ctt1g0b2x0

Danesi, M. (2019). Memes and the future of pop culture. Brill. https://doi.org/10.1163/25894439-12340001

Davison, P. (2012). The language of Internet memes. In M. Mandiberg (Ed.), The social media reader (pp. 120-134). New York University Press. http://hdl.handle.net/2027/heb.31970.0001.001

Dawkins, R. (1976). The selfish gene (40 ${ }^{\text {th }}$-anniversary edition). Oxford University Press.

Drodge, E. N., \& Reid, D. A. (2000). Embodied cognition and the mathematical emotional orientation. Mathematical Thinking and Learning, 2(4), 249-267.

Durand-Guerrier, V. (2008). Truth versus validity in mathematical proof. ZDM, 40, 373-384. https://doi.org/10.1007/s11858-008-0098-8

Douven, I. (2011). Abduction. In Edward N. Zalta (Ed.), The Stanford Encyclopedia of Philosophy (Summer Edition). Metaphysics Research Lab, Stanford University. https://plato.stanford.edu/archives/sum2017/entries/abduction/

Durkin, K., \& Shire, B. (1991). Lexical ambiguity in mathematical contexts. In K. Durkin \& B. Shire (Eds.), Language in Mathematical Education: Research and Practice (pp.7184). Milton Keynes, Bucks: Open University Press.

Eisenhardt, K.M. (1989). Building theories from case study research. Academy of Management Review, 14(4), 532-550. https://doi.org/10.2307/258557

Eisenhardt, K.M., \& Graebner, M.E. (2007). Theory building from cases: opportunities and challenges. Academy of Management Journal, 50(1), 25-32. https://doi.org/10.5465/amj.2007.24160888

Eisenhart, M. (1988). The ethnographic research tradition and mathematics education research. Journal for Research in Mathematics Education, 19(2), 99-114. https://doi.org/10.2307/749405

Freudenthal, H. (1971). Geometry between the devil and the deep sea. Educational Studies in Mathematics, 3, 413-435. https://doi.org/10.1007/BF00302305

Friske, A. L. (2018). Memes e matemática: processos de ensino e de aprendizagem guiados pela cyberformação [Memes and math: teaching and learning processes guided by cyberformation]. In Proceedings of the XXII Brazilian Meeting of Graduate Students in Mathematics Education (EBRAPEM). http://eventos.sbem.com.br/index.php/EBRAPEM/index/pages/view/anais2018

Gitelman, L. (2006). Always already new: Media, history and the data of culture. MIT Press.

Gleason, C., Pavel, A., Liu, X., Carrington, P., Chilton, L. B., \& Bigham, J. P. (2019). Making memes accessible. In ASSETS '19: The 21st International ACM SIGACCESS

This is the Accepted Manuscript of an article published by Taylor \& Francis in International Journal of Mathematical Education in Science and Technology on 26 September 2020, available at https://www.tandfonline.com/doi/full/10.1080/0020739X.2020.1807069 
Conference on Computers and Accessibility, (pp. 367-376).

https://doi.org/10.1145/3308561.3353792

Goldin, G.A. (2014). Mathematical representations. In S. Lerman (Ed.) Encyclopedia of Mathematics Education. Springer. https://doi.org/10.1007/978-94-007-4978-8_103

Gonçalves, P. G. F., \& Gonçalves, C. J. S. L. (2015). Um retrato da matemática segundo os memes: Potencialidade para o ensino-aprendizagem [A portrait of mathematics according to memes: Potential for teaching and learning]. Revista Tecnologias $\mathrm{Na}$ Educação, 7(13), 1-10. http://tecedu.pro.br/wp-content/uploads/2015/12/Art14-vol13dez2015.pdf

Gonçalves, P. G. F. (2016). Memes e educação matemática: Um olhar para as redes sociais digitais [Memes and math education: A look at digital social networks]. In Proceedings of XII Encontro Nacional De Educação Matemática (pp. 1-10). http://www.sbem.com.br/enem2016/anais/pdf/5825_2391_ID.pdf

Grandy, G. (2010). Instrumental case study. In A. J. Mills, G. Durepos, \& E. Wiebe (Eds.), Encyclopedia of case study research, (pp. 474-475). SAGE Publications, Inc. http://dx.doi.org/10.4135/9781412957397.n175

Gray, E., \& Tall, D. (1994). Duality, ambiguity and flexibility: A 'proceptual' view of simple arithmetic. Journal for Research in Mathematics Education, 25(2), 116-140.

Hand, M. (2016). Visuality in social media: Researching images, circulations and practices. In L. Sloan, \& A. Quan-Haase (Eds.) The SAGE Handbook of social media research methods (pp. 215-231). SAGE Publications Ltd.

Hanna, G. \& de Villiers, M. (2008). ICMI study 19: Proof and proving in mathematics education. ZDM-The International Journal of Mathematics Education, 40(2), 329336.

Harwati, L. N. (2019). Ethnographic and case study approaches: Philosophical and methodological analysis. International Journal of Education and Literacy Studies, 7(2), 150-155. http://dx.doi.org/10.7575/aiac.ijels.v.7n.2p.150

Harvey, L., \& Palese, E. (2018). \#NeverthelessMemesPersisted: Building critical memetic literacy in the classroom. Journal of Adolescent \& Adult Literacy 62(3), 259-270.

Huntington, H. E. (2013). Subversive memes: Internet memes as a form of visual rhetoric. AoIR Selected Papers of Internet Research, 3. https://journals.uic.edu/ojs/index.php/spir/article/view/8886

Huntington, H. E. (2017). The affect and effect of Internet memes: Assessing perceptions and influence of online user-generated political discourse as media [Doctoral dissertation, Colorado State University]. Mountain Scholar Digital Collection of Colorado \& Wyoming. https://mountainscholar.org/handle/10217/183936

Ito, M., Gutierrez, K., Livingstone, S., Penuel, B., Rhodes, J., Salen, K., \& Watkins, S.C. (2013). Connected learning: an agenda for research and design. Digital Media and Learning Research Hub. https://dmlhub.net/publications/connected-learning-agendafor-research-and-design/

Jenkins, H. (2006). Convergence culture: where old and new media collide. NYU Press.

This is the Accepted Manuscript of an article published by Taylor \& Francis in International Journal of Mathematical Education in Science and Technology on 26 September 2020, available at https://www.tandfonline.com/doi/full/10.1080/0020739X.2020.1807069 
Jenkins, H. (2009). Confronting the challenges of participatory culture. media education for the 21st century. MIT Press.

Jenkins, H. (2013). Spreadable media: creating value and meaning in a networked culture. New York University Press. https://www.jstor.org/stable/j.ctt9qfk6w

Jungwirth, H. (2003). Interpretative Forschung in der Mathematikdidaktik-ein Überblick für Irrgäste, Teilzieher und Standvögel [Interpretative research in the didactics of mathematics - An overview for vagrants, partial migrants and sedentary birds]. ZDM, 35, 189-200.

Kidron, I., Bikner-Ahsbahs, A., \& Dreyfus, T. (2011). How a general epistemic need leads to a need for a new construct: A case of networking two theoretical approaches. In M. Pytlak, T. Rowland, \& E. Swoboda (Eds.), Proceedings of the 7th Congress of the European Society for Research in Mathematics Education (pp. 2451-2461). University of Rzeszów, Poland.

Kilpatrick, J., Hoyles, C., \& Skovsmose, O. (2005). Meanings of 'Meaning of Mathematics'. In J. Kilpatrick et al. (Eds.), Meaning in Mathematics Education. (pp. 9-16). Springer. https://doi.org/10.1007/b104298

Knobel, M., \& Lankshear, C. (2005). Memes and affinities: Cultural replication and literacy education. Miami National Reading Conference. Retrieved June 24, 2020, from https://www.academia.edu/3011351/Memes_and_affinities_Cultural_replication_and_ literacy_education

Knobel, M., \& Lankshear, C. (2007). Online memes, affinities, and cultural production. In M. Knobel \& C. Lankshear (Eds.), A new literacies sampler (pp. 199-228). Peter Lang. https://researchonline.jcu.edu.au/3008/

Knobel, M., \& Lankshear, C. (2018). Memes online, afinidades e produção cultural (2007 2018) [Online memes, affinities and cultural production (2007 - 2018)]. Retrieved June 24, 2020, from https://doi.org/10.13140/rg.2.2.34717.77280

Kruglanski, A.W., Orehek, E., Dechesne, M., \& Pierro, A. (2010). Lay epistemic theory: The motivational, cognitive, and social aspects of knowledge formation. Social and Personality Psychology Compass, 4, 939-950. https://doi.org/10.1111/j.17519004.2010.00308.x

Lankshear, C., \& Knobel, M. (2003). New literacies: Changing knowledge and classroom learning. Open University Press. https://researchonline.jcu.edu.au/1796/

Marwick, A. (2013). Memes. Contexts, 12(4), 12-13. https://doi.org/10.1177\%2F1536504213511210

Milner, R. M. (2013). Pop polyvocality: Internet memes, public participation, and the occupy wall street movement. International Journal of Communication, 7, 2357-2390. https://ijoc.org/index.php/ijoc/article/view/1949

Miltner, K. M. (2014). “There's no place for lulz on LOLCats": The role of genre, gender, and group identity in the interpretation and enjoyment of an Internet meme. First Monday, 19(8). https://doi.org/10.5210/fm.v19i8.5391

This is the Accepted Manuscript of an article published by Taylor \& Francis in International Journal of Mathematical Education in Science and Technology on 26 September 2020, available at https://www.tandfonline.com/doi/full/10.1080/0020739X.2020.1807069 
O'Halloran, K. L. (2005). Mathematical discourse: Language, symbolism and visual images. Continuum.

Osterroth, A. (2018). Semiotics of Internet Memes. https://doi.org/10.13140/RG.2.2.12320.89605

Peirce, C.S. (1931). The Collected Papers V: Pragmatism and pragmaticism, 5, 189. https://www.textlog.de/7664-2.html

Pettigrew, A. (1990). Longitudinal Field Research on Change: Theory and Practice. Organization Science, 1(3), 267-292. www.jstor.org/stable/2635006 (Original work published 1988).

Priss U. (2018) A Semiotic-Conceptual Analysis of Conceptual Development in Learning Mathematics. In N. Presmeg, L. Radford, W. M. Roth, \& G. Kadunz (Eds.) Signs of Signification. ICME-13 Monographs (pp 173-188). Springer, Cham. https://doi.org/10.1007/978-3-319-70287-2_10

Pomerance, C., \& Spicer, C. (2019). Proof of the Sheldon conjecture. The American Mathematical Monthly, 126(8), 688-698. https://doi.org/10.1080/00029890.2019.1626672

Romero, E., \& Bobkina J. (2017). Teaching visual literacy through memes in the language classroom. In K. Donaghy \& D. Xerri (Eds.), The image in English language teaching (pp. 59-69). ELT Council Publisher.

https://www.teachingenglish.org.uk/sites/teacheng/files/The_Image_in_English_Lang uage Teaching.pdf

Santos, R. D., \& Carvalho, F. D. (2019). Meme e educação: práticas educativas em rede [Meme and education: networked educational practices]. Revista Periferia, 11(1), 7 15. https://doi.org/10.12957/periferia.2019.40063

Shifman, L. (2014). Memes in digital culture. MIT Press.

Silva, A. (2016, December 19). Digital literacies and visual rhetoric: Scaffolding a memebased assignment sequence for introductory composition classes. The Journal of Interactive Technology \& Pedagogy. https://jitp.commons.gc.cuny.edu/digitalliteracies-and-visual-rhetoric-scaffolding-a-meme-based-assignment-sequence-forintroductory-composition-classes/

Sloan, L., \& Quan-Haase, A. (2016). The SAGE Handbook of social media research methods. SAGE Publications Ltd. https://dx.doi.org/10.4135/9781473983847

Schmidt, A. (Host). (2014, April 28). Memes and the Internet hive mind [Audio podcast]. Cracked.

https://www.cracked.com/podcast/why-internet-turning-us-into-hive-mind/

Social Media Research Group (2016, June 14). Using social media for social research: An introduction. Government social research. http://dera.ioe.ac.uk/id/eprint/26600

Stryker, C. (2011). Epic Win for Anonymous: How 4chan's army conquered the Web. The Overlook Press.

This is the Accepted Manuscript of an article published by Taylor \& Francis in International Journal of Mathematical Education in Science and Technology on 26 September 2020, available at https://www.tandfonline.com/doi/full/10.1080/0020739X.2020.1807069 
Thomas, D., \& Seely Brown, J. (2011). A new culture of learning: Cultivating the imagination for a world of constant change. CreateSpace Independent Publishing Platform.

Ward-Penny, R. (2011). Memes and mathematics education. Philosophy of Mathematics Education Journal, 26.

http://socialsciences.exeter.ac.uk/education/research/centres/stem/publications/pmej/p ome26/index.html

Wells, D. D. (2018). You all made dank memes: Using Internet memes to promote critical thinking. Journal of Political Science Education, 14(2), 240-248. https://doi.org/10.1080/15512169.2017.1406363

Wenger, E. (1998). Communities of practice: Learning, meaning, and identity. Cambridge University Press. https://doi.org/10.1017/CBO9780511803932

Wiggins, B. E., \& Bowers, G. B. (2015). Memes as genre: A structurational analysis of the memescape. New Media \& Society, 17(11), 1886-1906. https://doi.org/10.1177/1461444814535194

Wilkins, D. P. (1996). Natural tendencies of semantic change and the search for cognates. In M. Durie, \& M. Ross (Eds.), The Comparative Method Reviewed, (pp. 264-304). Oxford University Press.

Yackel, E., \& Cobb, P. (1996). Sociomathematical norms, argumentation, and autonomy in mathematics. Journal for Research in Mathematics Education, 27(4), 458-477. https://doi.org/10.2307/749877

Yoon, I. (2016). Why is it not just a joke? Analysis of Internet memes associated with racism and hidden ideology of colorblindness. Journal of Cultural Research in Art Education, 33, 92-123. http://www.jcrae.org/journal/index.php/jcrae/article/view/60

This is the Accepted Manuscript of an article published by Taylor \& Francis in International Journal of Mathematical Education in Science and Technology on 26 September 2020, available at https://www.tandfonline.com/doi/full/10.1080/0020739X.2020.1807069 